\title{
Neuroprotective Effects of Adlay Hull Extract Against $\beta$-amyloid-induced Neurotoxicity and Lipopolysaccharide-induced Inflammatory Response
}

\author{
Jia-Zer Gregory Tsay \\ China Medical College Hospital: China Medical University Hospital \\ Yu-Ta Lin \\ Asia University Hospital \\ Chia-Hong Hsu \\ Asia University
}

Feng-Yao Tang

China Medical University

\section{Yueh-Hsiung Kuo}

China Medical University

Che-Yi Chao ( $\square$ cychao@asia.edu.tw)

Department of Food Nutrition and Health Biotechnology, Asia University, No. 500, Lioufeng Rd., Wufeng, Taichung 41354, Taiwan https://orcid.org/0000-0002-1819-7046

\section{Research}

Keywords: Adlay hull, $\beta$-amyloid peptide, Anti-oxidant, Anti-inflammatory, Apoptosis, Alzheimer's disease, Neuroprotection

Posted Date: October 19th, 2020

DOI: https://doi.org/10.21203/rs.3.rs-92824/v1

License: (c) (i) This work is licensed under a Creative Commons Attribution 4.0 International License. Read Full License 
Neuroprotective effects of adlay hull extract against $\beta$-amyloid-induced neurotoxicity and lipopolysaccharide-induced inflammatory response

Gregory J. Tsay ${ }^{1,2}$, Yu-Ta Lin $^{3 \S}$, Chia-Hong Hsu ${ }^{4}$, Feng-Yao Tang ${ }^{5}$, Yueh-Hsiung $\mathrm{Kuo}^{6,7,8}$, Che-Yi Chao ${ }^{4,9 *}$

${ }^{1}$ Division of Immunology and Rheumatology, China Medical University Hospital, Taichung, Taiwan, R.O.C.

${ }^{2}$ College of Medicine, China Medical University, Taichung, Taiwan, R.O.C.

${ }^{3}$ Division of Gastroenterology and Hepatobiliary, Asia University Hospital, Taichung, Taiwan, R.O.C.

${ }^{4}$ Department of Food Nutrition and Health Biotechnology, Asia University, Taichung, Taiwan, R.O.C.

${ }^{5}$ Biomedical Science Laboratory, Department of Nutrition, China Medical University, Taichung, Taiwan, R.O.C.

${ }^{6}$ Department of Chinese Pharmaceutical Sciences and Chinese Medicine Resources, China Medical University, Taichung, Taiwan, R.O.C.

${ }^{7}$ Department of Biotechnology, Asia University, Taichung, Taiwan, R.O.C.

${ }^{8}$ Chinese Medicine Research Center, China Medical University, Taichung, Taiwan, R.O.C.

${ }^{9}$ Department of Medical Research, China Medical University Hospital, China Medical University, Taichung, Taiwan, R.O.C.

§These authors contributed equally to this work.

*Correspondence to: Che-Yi Chao, Ph.D, Department of Food Nutrition and Health Biotechnology, Asia University, No. 500, Lioufeng Rd., Wufeng, Taichung 41354, Taiwan, R.O.C. Tel: +886-4-23323456 ext. 1859, e-mail: cychao@asia.edu.tw 


\begin{abstract}
Background: Nowadays, as technology and medical treatment improvements contribute to extending the lives of human beings, it also causes many diseases like noninfectious chronic and neurodegenerative with an aging population. Alzheimer's disease (AD) is one of the most common neurodegenerative diseases. It almost always occurs in older adults whose age is above 65 years old. AD is clinically characterized by a progressive loss of cognitive abilities. Pathologically, it is defined by the appearance of senile plaques-extracellular insoluble, congophilic protein aggregates composed of amyloid $\beta(\mathrm{A} \beta)$, resulting in oxidative stress, mitochondrial disorders, synaptic atrophy, leading to function degradation of the brain. The scientific name of adlay is Coix lacryma-jobi L., which is an annual botanical.
\end{abstract}

Methods: This research uses the adlay hull, as a test sample in the experiment. The 95\% ethanol extract of adlay hull (AHEE) was partitioned by ethyl acetate (AHEAE), $n$-butanol (AHBUE) and water (AHWE) subsequently, and the test of extracts by LPSinduce a RAW264.7 inflammatory response and $\mathrm{A} \beta_{25-35}$-induces $\mathrm{dPC} 12$ cells which cause neurotoxicity as an experimental model, respectively. Investigate the inflammatory and anti-apoptosis related protein expression.

Results: The results shown that the AHEE, AHEAE and AHWE exert antiinflammatory effects, AHWE also have anti-apoptosis effects. Through mouse macrophages inflammatory protein expression experiments, as well as inhibition of iNOS expression, resulted in inhibited nitrite production. In this study, we investigated the protective effects of AHWE against the $A \beta_{25-35}$-induced neurotoxicity in $\mathrm{dPC} 12$ cells and explored the underlying mechanism. The results showed that pretreatment with AHWE significantly attenuated cell death and the elevated Bax/Bcl-2 ratio evoked by $A \beta_{25-35}$. Moreover, AHWE significantly inhibited $A \beta_{25-35}$ and enhanced the protein levels of Akt in dPC12 cells. These observations unambiguously suggested that the protective effect of AHWE against $A \beta_{25-35}$-induced apoptosis in $\mathrm{dPC} 12$ cells was associated with the enhancement of the PI3K/Akt signaling pathway.

Conclusion: The results showed that adlay hull extracts have the anti-oxidant, antiinflammatory, anti-apoptotic and neuroprotective property. These results suggest that adlay hull extracts may have a preventive therapeutic potential in the management of $\mathrm{AD}$.

Keywords: Adlay hull, $\beta$-amyloid peptide, Anti-oxidant, Anti-inflammatory, Apoptosis, Alzheimer's disease, Neuroprotection 


\section{Background}

Due to the rapid development of modern technology, with the advancement of medical treatment, people's average life expectancy has been extended, which has led to a rapid aging of the population. With the increase of age, chronic diseases and neurodegenerative diseases also follow. Alzheimer's disease (AD) is a common neurodegenerative disease that often occurs in elderly people over 65 years old, causing memory loss and a cognitive decline in patients that strongly interfere with normal daily life. The generation of oxygen free radicals, reactive oxygen species (ROS), and oxidative stress is believed to be involved in the pathogenesis of neurodegenerative disorders (Kim et al., 2011). AD is caused by the accumulation of $\beta$-amyloid (A $\beta$ ) peptide and $\mathrm{A} \beta$ plaques in the brain. $\mathrm{AD}$ is a complex disease and its neurodegenerative molecular mechanism is not yet fully understood. Growing evidence suggests a link between $\mathrm{A} \beta$ polymorphic nature, oligomers and fibrils, and specific mechanisms of neurodegeneration (Picone et al., 2020).

Oxidative stress, nerve inflammation, and synapse atrophy, which in turn leads to the deterioration of brain function. $A \beta$ peptide and its aggregates are the main components of senile plaques and evidences from in vivo and in vitro experiments have shown that $A \beta$-induced neurotoxicity contributes to the pathogenesis and progression of $\mathrm{AD}$ (Citron, 2002). Accumulation of $\mathrm{A} \beta$ peptide causes an increase in intracellular reactive free radicals and ROS. Increased ROS and free radicals due to the A $\beta$ peptide leads to accumulation of lipid peroxidation, protein oxidation, and oxidation of mitochondrial DNA (Markesbery \& Carney, 1999). The underlying mechanism of A $\beta$ induced neurotoxicity is not yet fully understood but appears to involve several pathways associated with apoptosis, which in turn may lead to the neuronal degeneration in $\mathrm{AD}$ (Yao et al., 2005). AD is a heterogeneous disease with a complex pathobiology. The presence of extracellular amyloid- $\beta$ deposition as neuritic plaques and intracellular accumulation of hyperphosphorylated tau as neurofibrillary tangles remain the primary neuropathologic criteria for $\mathrm{AD}$ diagnosis. (Long \& Holtzman, 2019). Therefore, inhibition of $A \beta$-induced neuronal apoptosis may provide a possible approach for $\mathrm{AD}$ prevention and treatment.

Adlay is an annual herb of the Gramineae Coix genus, and is often used as an edible or medicinal grain in Asian countries. Adlay (Coix lachryma-jobi L.) seeds have long been used to treat warts, chapped skin, rheumatism, and neuralgia in traditional Chinese medicine (TCM). Recently, studies demonstrated its anti-inflammatory, antiproliferative, anti-tumor, and anti-allergic activities (Wang et al., 2013). Many studies have indicated that adlay has rich physiologically active ingredients, including longchain fatty alcohols, phytosterols and oleamide, which have anti-oxidation, antiinflammatory, anti-tumor, blood lipid lowering health effects (Kuo et al., 2002; Huang 
et al., 2009; Chung et al., 2011, Yu et al., 2011). A few studies have reported that extracts of adlay hull have neuroprotective effects. However, the effects of adlay hull extracts on neuronal cell oxidative damage and neuroinflammatoion due to the $A \beta$ peptide are unknown.

In this study, we investigated the preventive effect of adlay hull extracts against $\mathrm{A} \beta$ peptide-induced oxidative stress by assessing free radical scavenging, cell viability, and inflammatory mediator. This study uses a cellular model to investigate the physiological changes and possible mechanisms of the adlay hull agricultural waste on neurodegenerative diseases caused by oxidative stress and inflammation. We hope this research can confirm the multi-functional nutritional and health benefits of adlay hull, and to innovate the value of agricultural products, so that agricultural waste can be reused to achieve the development of sustainable agriculture. In the future, there is an opportunity to develop agricultural waste into the elder's health food.

\section{Materials and methods}

\section{Experimental samples and extraction methods}

The experimental samples were taken from the Taichung No. 3 Coix lacryma-jobi L. of the Caotun Adlay Production Cooperative in Nantou County. The seed coat was removed by a screening machine to obtain the adlay hull. The obtained adlay hull is made into powder with a grinder for extraction. The extraction method is that the adlay hull powder is soaked in 95\% ethanol for three days as the ethanol extract (AHEE). After suction and filtration, the ethanol is removed by a rotary evaporator. The sample is re-dissolved with deionized water and placed in a separatory funnel. Ethyl acetate and $n$-butanol were partitioned and extracted and then concentrated under rotary evaporator to obtain ethyl acetate partitioned extract (AHEAE), $n$-butanol partitioned extract (AHBUE) and water partitioned extract (AHWE). The obtained organic extracts were re-dissolved in absolute alcohol to prepare stocks, and the aqueous extract was redissolved in PBS to prepare stocks. The extracts were stored in a refrigerator at $-20^{\circ} \mathrm{C}$ for subsequent experimental analysis.

\section{General ingredients analysis}

a. Moisture content determination

Place the weight of $2 \mathrm{~g}$ of fresh sample $\left(\mathrm{W}_{1}\right)$ into a crucible $\left(\mathrm{W}_{0}\right)$ that has been weighed and dried in an oven at $105^{\circ} \mathrm{C}$ for 24 hours to reach a constant weight $\left(\mathrm{W}_{0}\right)$, and the crucible containing the sample is placed in an oven at $105^{\circ} \mathrm{C}$ for repeated drying. Cool, weigh to constant weight ( $\left.\mathrm{W}_{2}\right)$, and divide the weight loss by the original sample weight to obtain the sample moisture content. The moisture content $(\%)$ calculation formula is equal to $\left[\mathrm{W}_{1}-\left(\mathrm{W}_{2}-\mathrm{W}_{0}\right)\right] / \mathrm{W}_{1} \times 100$. 


\section{b. Ash content determination}

Place the weight of $2 \mathrm{~g}$ of the dried sample $\left(\mathrm{W}_{1}\right)$ into a crucible $\left(\mathrm{W}_{0}\right)$ that has been weighed and dried in a $105^{\circ} \mathrm{C}$ oven for 24 hours to reach a constant weight, placed in a $550^{\circ} \mathrm{C}$ ash furnace, heated for 24 hours, and then dried. Weigh the box after it has dropped to room temperature $\left(\mathrm{W}_{2}\right)$. The sample ash content $(\%)$ calculation formula is equal to $\left[\mathrm{W}_{1-}\left(\mathrm{W}_{2}-\mathrm{W}_{0}\right)\right] / \mathrm{W}_{1} \times 100$.

\section{c. Crude fat content determination}

Place the weight of $2 \mathrm{~g}(\mathrm{~W})$ of the dried sample into a cylindrical filter paper, cover it with absorbent cotton, and then take a round-bottomed flask dried in a $105^{\circ} \mathrm{C}$ oven for 24 hours to reach a constant weight. Take the weight $\left(\mathrm{W}_{1}\right)$, and place the cylindrical filter paper into Soxhlet in the middle section of the extraction tube of the extraction device, fill the round-bottom flask with $150 \mathrm{~mL}$ of ether and place it in the $55^{\circ} \mathrm{C}$ constant temperature water bath for continuous extraction for 18 hours. After extraction, remove the condenser tube and take out the cylindrical filter paper, recover the ether, put the round-bottom flask in the air extraction cabinet to volatilize the remaining ether, then put it in a $105^{\circ} \mathrm{C}$ oven for 24 hours, and finally put it in a drying oven to reduce to the room temperature. Then weigh after cooling down to room temperature $\left(\mathrm{W}_{2}\right)$. Sample lipid content $(\%)$ calculation formula is equal to $\left[\left(\mathrm{W}_{2}-\mathrm{W}_{1}\right) / \mathrm{W}\right] \times 100$.

\section{d. Crude protein content determination}

Place the weight of $2 \mathrm{~g}$ (W) of the dried sample into the decomposition flask, add 25 $\mathrm{mL}$ of concentrated sulfuric acid and potassium sulfate (protein catalyst), heat to decompose until the solution is clear. Then put it into the Kjeldahl nitrogen distillation device for distillation and add alkali liquid $(40 \% \mathrm{NaOH})$ which is distilled for 6 minutes. The outlet is received with a mixed indicator (Bromocresol green + Methyl red) boric acid solution $(4 \%, 25 \mathrm{~mL})$, and finally titrated with $0.1 \mathrm{~N}$ hydrochloric acid standard solution until the pink color appears. Record the consumed milliliters of hydrochloric acid $\left(\mathrm{V}_{1}\right)$, and record the consumed milliliters of hydrochloric acid $\left(\mathrm{V}_{2}\right)$ as the blank group. The calculation formula of sample crude protein content $(\%)$ is equal to $\left[\left(\mathrm{V}_{1}-\mathrm{V}_{2}\right)\right.$ $\times \mathrm{F} \times 0.014 \times \mathrm{N}] / \mathrm{W} \times 100 . \mathrm{F}$ is the titer of $0.05 \mathrm{~N} \mathrm{NaOH}$ standard solution, $\mathrm{N}$ is the nitrogen coefficient.

\section{Determination of antioxidant capacity}

a. DPPH free radical scavenging ability measurement

Dilute the experimental samples with ethanol to concentrations of $0.25,0.5,1$ and 2 $\mathrm{mg} / \mathrm{mL}$ and use the same concentration of Gallic acid as the control group. The DPPH 
solution is mixed with samples of different concentrations and Gallic acid in a ratio of $1: 4$, and the reaction is protected from light. For 30 minutes, use an ELISA reader to detect the change in absorbance at a wavelength of $517 \mathrm{~nm}$. The lower the absorbance value, the stronger the ability to remove DPPH.

\section{b. Total phenol content measurement}

Folin-Ciocalteu's assay was used to evaluate the total phenol content of the sample. Dilute the sample with ethanol to $2 \mathrm{mg} / \mathrm{mL}$, take $50 \mu \mathrm{L}$ of the diluted sample, add 50 $\mu \mathrm{L}$ Folin-Ciocalteu's phenol reagent, mix well and add $700 \mu \mathrm{L}$ deionized water, mix evenly and let stand for 3 minutes. Add $200 \mu \mathrm{L} 20 \% \mathrm{Na}_{2} \mathrm{CO}_{3}$ solution, immediately react in a water bath at $100^{\circ} \mathrm{C}$ for 1 minute, avoid light and wait for the sample to cool, and measure the change in absorbance at $700 \mathrm{~nm}$. According to the same method, different concentrations of Gallic acid are used as samples, and the absorbance value changes are calculated to obtain the regression equation of the standard curve. The absorbance value of the sample can be substituted into the sample to calculate the Gallic acid equivalent.

\section{A $\boldsymbol{\beta}_{25-35}$ preparation}

A $325-35$ (Sigma, St. Louis, MO. USA), which is the most toxic peptide fragment derived from amyloid precursor protein, was dissolved in deionized distilled water and incubated with constant oscillation at $37^{\circ} \mathrm{C}$ for 3 days to induce its aggregation. After aggregation, the solution was stored at $-20^{\circ} \mathrm{C}$ until use. The stock solution was diluted to desired concentrations immediately before use and added to cell culture medium.

\section{Cell culture and treatment}

RAW264.7 cells were purchased from American Type Culture Collection (ATCC; Manassas, VA, USA) and were cultured in Dulbecco's modified Eagle's medium (HyClone, Logan, UT, USA) supplemented with $2 \mathrm{mM}$ glutamine, antibiotics (100 units $/ \mathrm{mL}$ penicillin and $100 \mu \mathrm{g} / \mathrm{mL}$ streptomycin), and $10 \%$ fetal bovine serum at $37^{\circ} \mathrm{C}$ and $5 \% \mathrm{CO}_{2}$. The cells were treated with different adlay hull extracts in the presence of LPS (100 ng/mL) for 24 hours for further measurements. The undifferentiated PC-12 cells were obtained from the American Type Culture Collection (ATCC; Manassas, VA, USA). They were routinely maintained in 85\% RPMI 1640 medium with 2 mM Lglutamine adjusted to contain $1.5 \mathrm{~g} / \mathrm{L}$ sodium bicarbonate, $10 \%$ heat-inactivated horse serum and 5\% fetal bovine serum (FBS), 100 units $/ \mathrm{mL}$ penicillin and $100 \mu \mathrm{g} / \mathrm{mL}$ streptomycin and differentiated with $50 \mathrm{ng} / \mathrm{mL}$ of NGF in RPMI medium with $1 \% \mathrm{FBS}$ and penicillin/streptomycin ( $1 \%$ FBS-NGF medium) at $37^{\circ} \mathrm{C}$ in a humidified atmosphere of $95 \%$ air and $5 \% \mathrm{CO}_{2}$. The medium was replaced every 3 days and $\mathrm{PC} 12$ 
cells were differentiated for 7-10 days before treatments. In all experiments, dPC-12 cells were seeded into 24 -well multi-plates $\left(1 \times 10^{5}\right.$ cells/well $)$. After 24 hours, the cells were pretreated in the absence or in the presence of AHEE, AHEAE, AHBUE, AHWE $(600 \mu \mathrm{g} / \mathrm{mL})$ for a period of 24 hours, followed by incubating with $A \beta_{25-35}(20 \mu \mathrm{M})$ for an additional 24 hours.

\section{MTT assay}

Cell viability was estimated by the MTT reduction assay, which is based on the conversion of MTT to formazan crystals by mitochondrial dehydrogenases. Following incubation for 24 hours at $37^{\circ} \mathrm{C}$ and $5 \% \mathrm{CO}_{2}$, the supernatant was removed and $100 \mu \mathrm{L}$ dimethyl sulfoxide added to each well to dissolve the formazan. Absorbance was measured using the ELISA reader at a wavelength of $570 \mathrm{~nm}$. Cell viability was normalized as relative percentages in comparison with untreated controls.

\section{Nitrite assay}

Trypsinize the RAW264.7 confluency cells, dilute them with culture medium to $4 \times 10^{5}$ cells $/ \mathrm{mL}$, seed them in a 96 -well plate, add $100 \mu \mathrm{L}$ of cell fluid to each well, and culture in a $37^{\circ} \mathrm{C}, 5 \% \mathrm{CO}_{2}$ incubator for 18 to 24 hours. Remove the original medium, add the test sample and LPS (100 ng/mL) for a total volume of $100 \mu \mathrm{L} /$ well. After incubating for 18 hours in the incubator, transfer of supernatant from each well to another 96-well plate. Add the mixed Griess reagent $100 \mu \mathrm{L} /$ well, and react for 10 minutes in the dark. Use an ELISA reader to detect the absorbance at $540 \mathrm{~nm}$. Take the absorbance against the standard curve to calculate the nitrite content.

\section{Superoxide Dismutase (SOD) activity determination}

After collecting a certain number of cells, add $1 \mathrm{~mL}$ of cell lysate $(20 \mathrm{mM}$ HEPES buffer, $\mathrm{pH} 7.2$, containing $1 \mathrm{mM}$ EGTA, $210 \mathrm{mM}$ mannitol, and $70 \mathrm{mM}$ sucrose), centrifuge at $1500 \times g$ for 5 minutes, and collect the supernatant at $4^{\circ} \mathrm{C}$ for use. In a 96-well plate, add $200 \mu \mathrm{L}$ diluted radical detector and $10 \mu \mathrm{L}$ sample supernatant to each well, then add $20 \mu \mathrm{L}$ diluted xanthine oxidase to stop the reaction, react at room temperature for 30 minutes, and finally detect the absorbance at $450 \mathrm{~nm}$ with the ELISA reader. Use different concentrations of SOD stock as the absorbance value change of the standard to obtain the regression equation of the standard curve, and substitute the absorbance value of the sample to get the SOD activity.

$$
\mathrm{SOD}(\mathrm{U} / \mathrm{mL})=\left[\left(\frac{\text { sampleLR-y-intercept }}{\text { slope }}\right) \times \frac{0.23 \mathrm{~mL}}{0.01 \mathrm{~mL}}\right] \times \text { sample dilution }
$$

\section{Catalase (CAT) activity determination}


After collecting a certain number of cells, add $1 \mathrm{~mL}$ of cell lysate $(50 \mathrm{mM}$ potassium phosphate, $\mathrm{pH} 7.0$, containing $1 \mathrm{mM}$ EDTA), centrifuge at $10,000 \times g$ for 15 minutes, collect the supernatant at $4^{\circ} \mathrm{C}$ for use. In a 96-well plate, add $100 \mu \mathrm{L}$ assay buffer, 30 $\mu \mathrm{L}$ methanol and $20 \mu \mathrm{L}$ sample to each well. Start the reaction by quickly adding $20 \mu \mathrm{L}$ $\mathrm{H}_{2} \mathrm{O}_{2}$ to each well. Shake at room temperature for 20 minutes to make the reaction. Add $30 \mu \mathrm{L} \mathrm{KOH}$ and $30 \mu \mathrm{L}$ catalase, shake at room temperature for 10 minutes until the reaction is complete, and finally add $10 \mu \mathrm{L}$ catalase potassium periodate to each well to stop the reaction, shake at room temperature for 5 minutes until the reaction is complete, and finally detect the absorbance at $540 \mathrm{~nm}$ with the ELISA reader. Calculate the regression equation of the standard curve with the absorbance change of different concentrations of CAT stock as the standard. Substitute the absorbance of the sample to get the CAT activity.

CAT Activity $=\frac{\mu \mathrm{M} \text { of sample }}{20 \mathrm{~min}} \times$ sample dilution $=\mathrm{nmol} / \mathrm{min} / \mathrm{mL}$

\section{Western blot analysis}

For the Western blot analysis, treated or untreated cells were lysed in RIPA buffer (25 $\mathrm{mM}$ Tris- $\mathrm{HCl}, 150 \mathrm{mM} \mathrm{NaCl}, 1 \% \mathrm{NP}-40,1 \%$ sodium deoxycholate, $0.1 \% \mathrm{SDS}, \mathrm{pH} 7.6$, Sigma-Aldrich) to prepare protein extracts as previously described (Napolitano et al., 2011) and the protein concentrations were determined using the Bradford protein assay method. Each equal amount of total cell proteins $(20 \mu \mathrm{g})$ were loaded and separated by $10 \%$ SDS poly-acrylamide gel electrophoresis (SDS-PAGE) and transferred to PVDF membranes by electro-blotting. After the membranes were blocked in 5\% non-fat milk for 1 hour at room temperature, the membranes were probed with primary antibodies (anti-iNOS, anti-GAPDH; anti-Bcl-2, anti-Bax, anti-p-Akt, anti-PI3K, anti- $\beta$-actin; Cell Signaling Technology, Danvers, MA, USA) overnight at $4^{\circ} \mathrm{C}$. GAPDH and $\beta$-actin were used for a control for protein loading in each lane. The blots were washed, incubated with horseradish-peroxidase-conjugated secondary antibody $(1: 2000)$ for 2 hours at room temperature and then subjected to autoradiography using an ECL Western blotting Detection kit from Amersham Pharmacia (Amersham Pharmacia Biotech, Perkin Elmer, Waltham, USA). Signals were visualized using a chemiluminescence image analysis system to develop color (Image Quant LAS 4000 mini, 0622193, GE Healthcare, San Diego, USA).

\section{Statistical analysis}

Data are presented as means $\pm \mathrm{SD}$ of three replicates. Values of $P<0.05$ were considered as statistical significance by one-way analysis of variance with Duncan's multiple range test using SPSS (Statistics Package Social Science) software ${ }^{\circledR}$. The 
Student's $t$-test was performed to analyze differences between groups, with $P<0.01$ indicating a statistically significant difference.

\section{Results}

\section{Component analysis of adlay hull}

In this experiment, the moisture, crude fat, crude protein and ash content of dried adlay hull were measured, and then the content of carbohydrates are able to be calculated after deducting the moisture, crude fat, crude protein and ash content by $100 \%$. Each item is expressed in percentages (\%). The results are shown in Table 1. moisture 7.69\%, ash $10.71 \%$, crude fat $5.34 \%$, crude protein $11.27 \%$, carbohydrate $64.99 \%$.

\section{Yield of different extraction fractions of adlay hull}

A sample of $6105 \mathrm{~g}$ of adlay hull, dried and ground into powder, was extracted with ethanol to obtain $12.21 \mathrm{~g}$ of ethanol extract with a yield of $0.2 \%$. Then take the ethanol extract for partition extraction, and obtain $5.08 \mathrm{~g}$ ethyl acetate fraction extract, $1.46 \mathrm{~g}$ n-butanol fraction extract, and $4.21 \mathrm{~g}$ water fraction extract. The yields are $41.6 \%$, $12.0 \%$, and $34.5 \%$, respectively which are listed in Table 2 .

\section{Antioxidant ability of different extracts of adlay hull}

The results of scavenging DPPH free radicals of different extracts of adlay hull are shown in Figure 1(a). The scavenging ability of each extract of AHEAE, AHBUE and AHWE is equal to the positive control gallic acid at a concentration of $2 \mathrm{mg} / \mathrm{mL}$, while AHEAE and AHBUE are at low concentrations of $0.5 \mathrm{mg} / \mathrm{mL}$ and $1 \mathrm{mg} / \mathrm{mL}$, it has the ability to scavenge free radicals. The results of the total phenol content of different extracts of adlay hull were shown in Figure 1(b). The content of AHBUE is significantly higher than other extracts. Each gram of AHBUE contains $70.86 \mathrm{mg}$ of relative gallic acid.

Effects of different extracts of adlay hull on survival rate and nitrite production in

\section{RAW264.7 cells}

The result was shown in Figure 2. LPS $(100 \mathrm{ng} / \mathrm{mL})$ was used to induce inflammation of RAW264.7 cells, and different extracts of adlay hull were treated to observe the production of nitrite, the inflammatory mediator, without affecting cell survival. It was found that the AHEE, AHEAE and AHWE samples have the effect of inhibiting the formation of nitrite. The effect of inhibiting the formation of nitrite at a concentration of $100 \mu \mathrm{g} / \mathrm{mL}$ is $38.2 \%, 52.3 \%$ and $59.1 \%$, respectively. 


\section{Effects of different extracts of adlay hull on iNOS protein expression in RAW264.7 cells}

The result was shown in Figure 3. The ethanol extract of adlay hull (AHEE) can significantly reduce the expression of iNOS protein and the inhibitory effect is better than that of the positive control (dexamethasone). Among the different extracts of adlay hull, AHEE had the best effect in reducing iNOS protein expression, followed by AHEAE, and AHBUE had the worst effect.

\section{The cell survival rate of different extracts of adlay hull in dPC12 cells}

$20 \mu \mathrm{M} \mathrm{A} \beta_{25-35}$ was used to induce neurotoxicity in $\mathrm{dPC} 12$ cells, and different extracts of adlay hull were treated, and the effects of different extracts of adlay hull in protecting nerve cells were observed without affecting the cell survival rate. The results are shown in Figure 4, indicating both AHBUE and AHWE can protect nerve cells at a concentration of $600 \mu \mathrm{g} / \mathrm{mL}$, and the neuroprotective effect of AHWE is better than that of AHBUE.

\section{Antioxidant effect of different extracts of adlay hull in dPC12 cells}

The SOD activity of different extracts of adlay hull in dPC12 was shown in Figure 5(a). AHBUE has the highest SOD activity at a concentration of $600 \mu \mathrm{g} / \mathrm{mL}$, about 10.99 $\mathrm{U} / \mathrm{mL}$. The results of catalase activity of different extracts of adlay hull in dPC12 are shown in Figure 5(b). Different extracts of adlay hull can increase the activity of CAT.

\section{The effect of different extracts of adlay hull with $\mathbf{A} \boldsymbol{\beta}_{25-35}$ inducing protein expression in dPC12 cells}

The expression of $\mathrm{PI} 3 \mathrm{~K}$ protein of $\mathrm{dPC} 12$ cells after treatment with different extracts of the adlay hull increased significantly $(P<0.05)$. In addition, AHWE activated PI3K protein and showed the best performance is shown in Figure 6(a). The expression of pAkt protein in dPC12 cells treated with AHWE was significantly increased when compared with the control group $(P<0.05)$. AHWE has the best effect of activating pAkt protein is shown in Figure 6(b). The expression of Bcl-2 protein of dPC12 cells treated with AHWE was significantly increased when compared with the control group $(P<0.05)$. AHWE has the best effect of activating Bcl-2 protein as shown in Figure 6(c). The Bax protein expression of dPC12 cells treated with AHWE was significantly reduced when compared with the control group $(P<0.05)$. AHWE has the best inhibitory effect on Bax protein as shown in Figure 6(d). The results of different extracts of adlay hull on the Bcl-2/Bax protein expression of dPC12 cells are shown in Figure 7. After the $\mathrm{dPC} 12$ cells were treated with AHWE, the ratio of Bcl-2/Bax increased significantly 
when compared with the control group $(P<0.05)$. AHWE has the best anti-apoptotic effect. 
Table 1 The general composition analysis of adlay hull

item

contents $(\%)$

\begin{tabular}{lr}
\hline Moisture & $7.96 \pm 2.79$ \\
Ash & $10.71 \pm 3.44$ \\
Crude fat & $5.34 \pm 1.72$ \\
Crude protein & $11.27 \pm 3.21$ \\
Carbohydrate & $64.99 \pm 0.00$ \\
\hline
\end{tabular}

Values are means $\pm \mathrm{SD}(\mathrm{n}=3)$ 
Table 2 The yield of different adlay hull extracts and partition fractions

\begin{tabular}{cccc}
\hline item & $\begin{array}{c}\text { original sample } \\
\text { weight }(\mathrm{g})\end{array}$ & $\begin{array}{c}\text { net weight of } \\
\text { extract }(\mathrm{g})\end{array}$ & yield* (\%) \\
\hline AHEE & 6105 & 12.21 & 0.2 \\
AHEAE $^{\#}$ & 12.21 & 5.08 & 41.6 \\
AHBUE $^{\#}$ & 12.21 & 1.46 & 12.0 \\
AHWE $^{\#}$ & 12.21 & 4.21 & 34.5 \\
\hline
\end{tabular}

$*$ yield $(\%)=($ net weight of extract / original sample weight $) \times 100$

\# means the extracts were partitioned from AHEE

AHEE: adlay hull ethanol extract

AHEAE: adlay hull ethyl acetate extract partition fraction

AHBUE: adlay hull $n$-butanol extract partition fraction

AHWE: adlay hull water extract partition fraction 
(a)

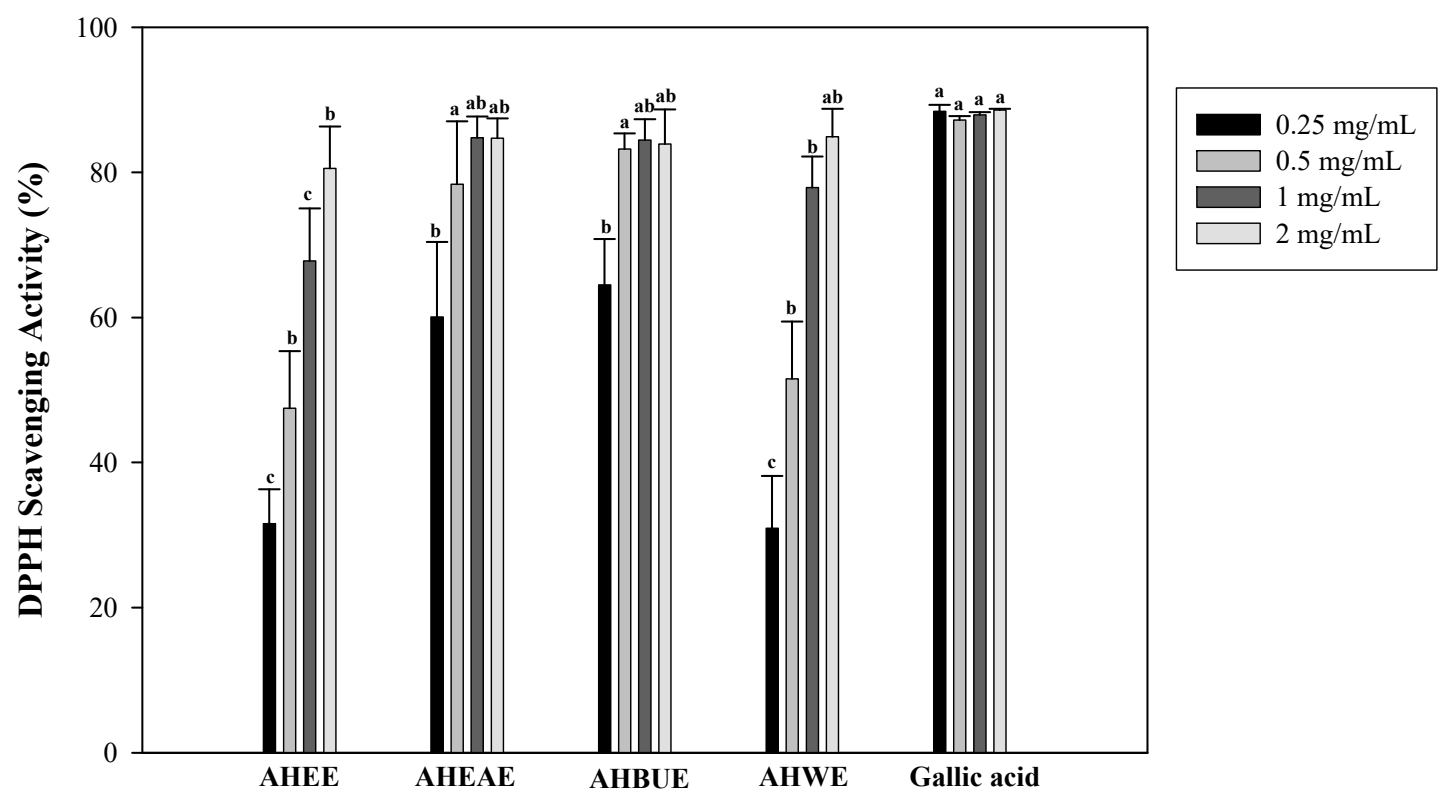

(b)

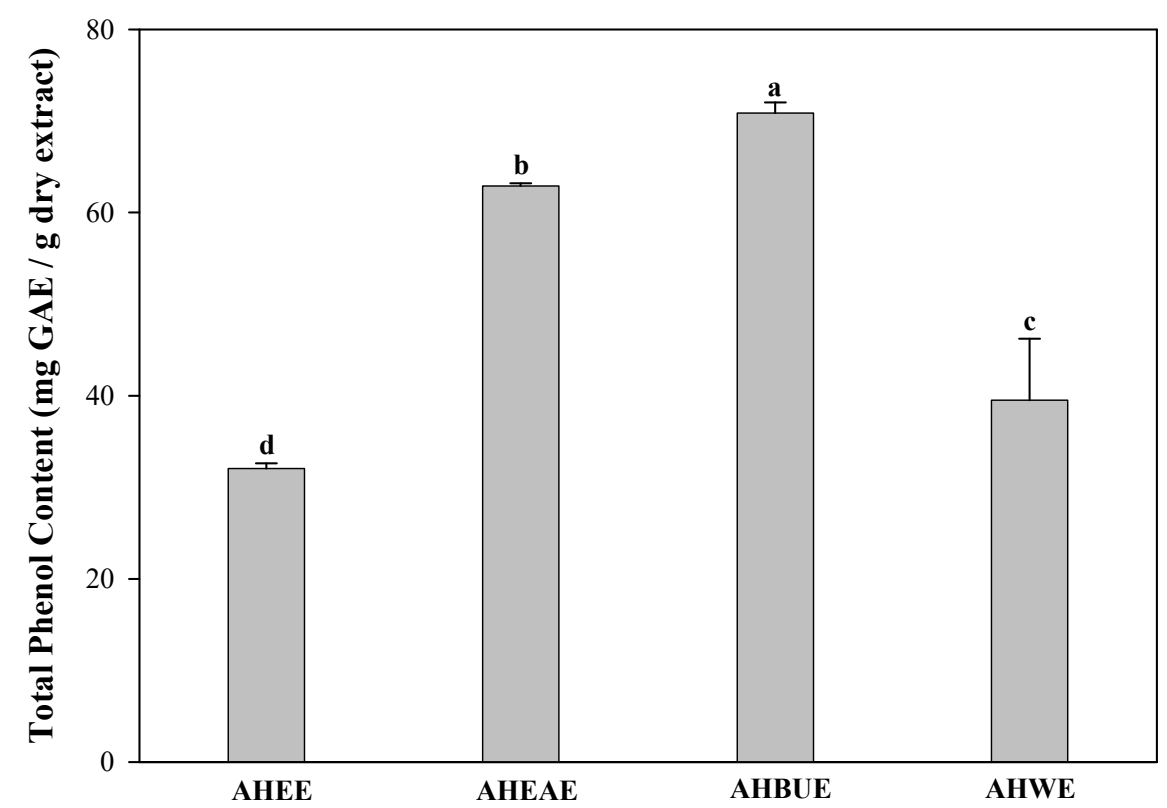

Fig. 1 (a) The DPPH scavenging activity of the adlay hull extracts. (b) The total phenol contents of the adlay hull extracts. The values are the means $\pm \operatorname{SD}(n=3)$ and analyzed using one-way ANOVA, followed by Duncan's new multiple range test. The superscript letters indicate significant differences $(P<0.05)$. 


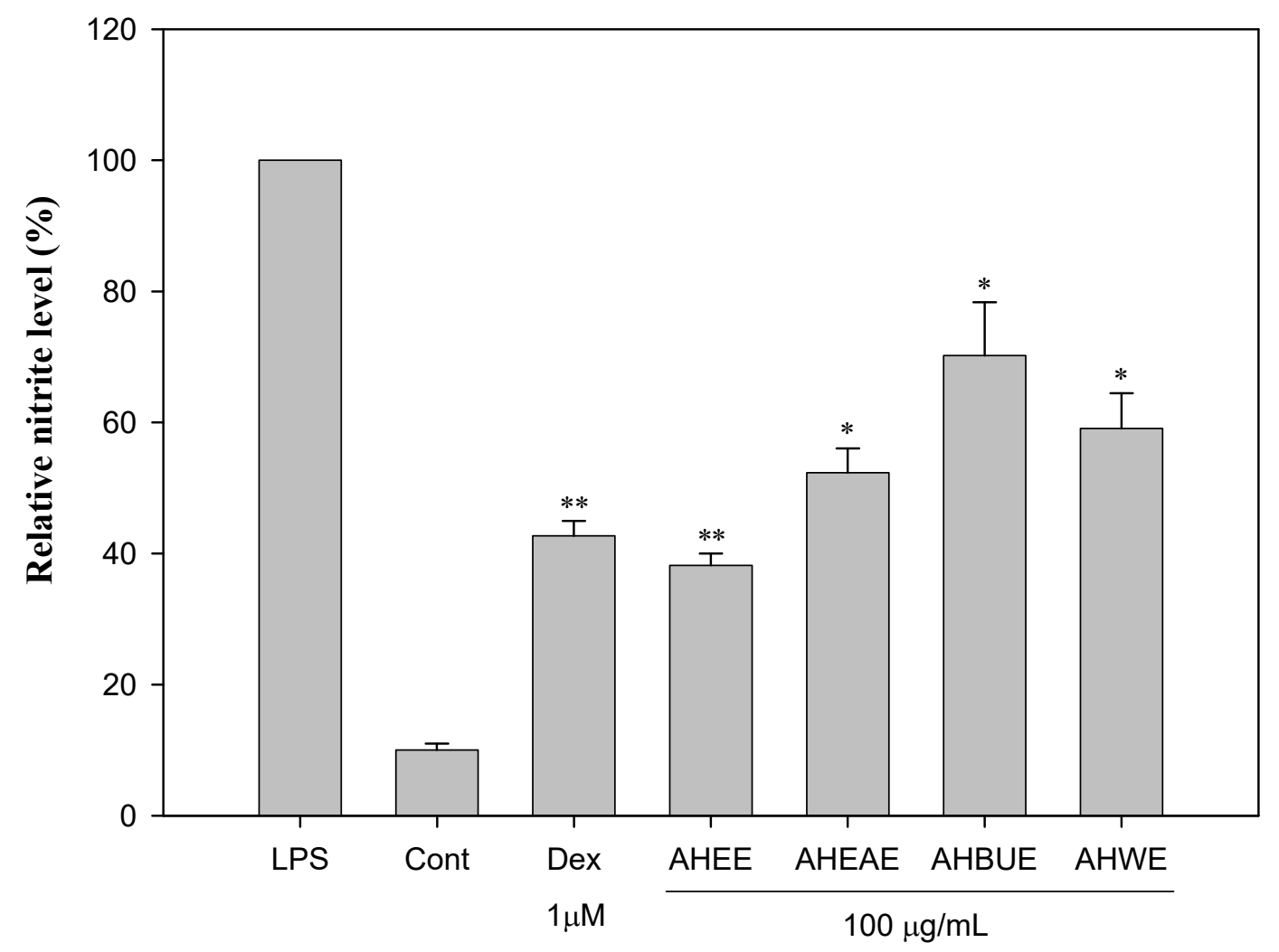

Fig. 2 Effects of the different adlay hull extracts on nitrite production in RAW264.7 cells. The values are the means $\pm \mathrm{SD}(\mathrm{n}=3)$ and statistical analysis was done using the Student's $t$-test. ${ }^{*} P<0.01 ; * * P<0.001$, were significantly different from the control group. Dexamethasone at the concentration of $1 \mu \mathrm{M}$ was used as a positive control; cells were treated with $100 \mathrm{ng} / \mathrm{mL}$ LPS to induce inflammation. 

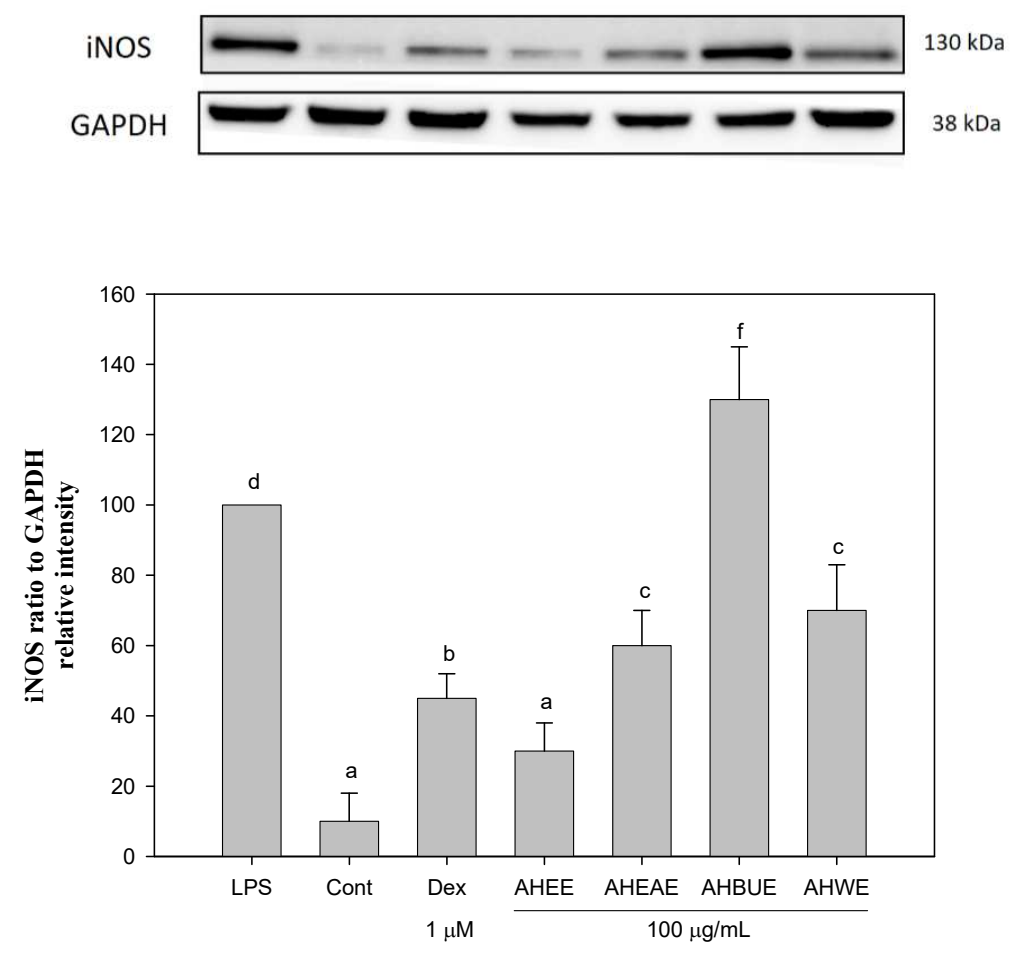

Fig. 3 Effects of the different adlay hull extracts on iNOS protein expression in RAW264.7 cells. The total cellular protein $(20 \mu \mathrm{g} / \mathrm{lane})$ was separated on a $10 \%$ SDSPAGE, transferred to a PVDF membrane and stained with antibodies specific for iNOS. The values are the means $\pm \mathrm{SD}(\mathrm{n}=3)$ and analyzed using one-way ANOVA, followed by Duncan's new multiple range test. Bars that do not share a common letter are significantly different $(P<0.05)$ from each other. Dexamethasone at the concentration of $1 \mu \mathrm{M}$ was used as a positive control; cells were treated with $100 \mathrm{ng} / \mathrm{mL}$ LPS to induce inflammation. 


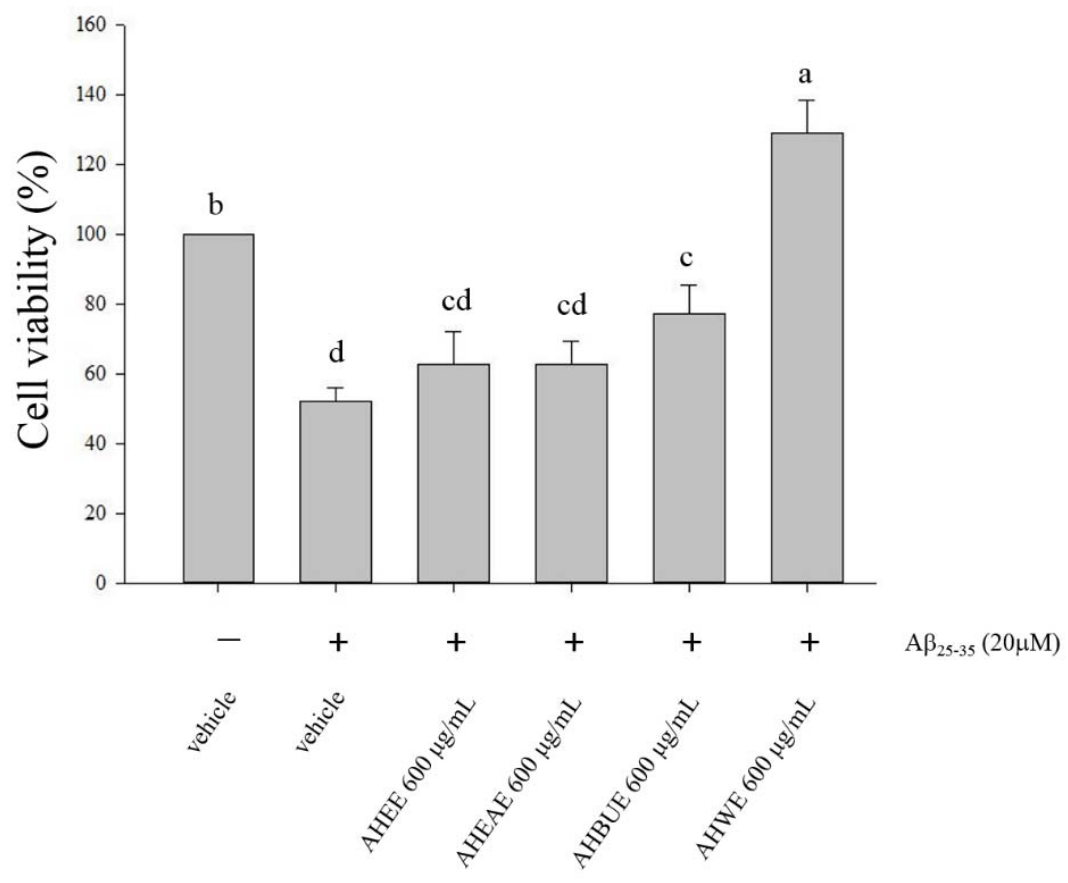

Fig. 4 MTT assay of the different adlay hull extracts to neuroprotection in dPC12 cells. The values are the means $\pm \mathrm{SD}(\mathrm{n}=3)$ and analyzed using one-way ANOVA, followed by Duncan's new multiple range test. Bars that do not share a common letter are significantly different $(P<0.05)$ from each other. The cells were treated with $20 \mu \mathrm{M}$ $\mathrm{A} \beta \beta_{25-35}$ to induce neurotoxicity. 
(a)

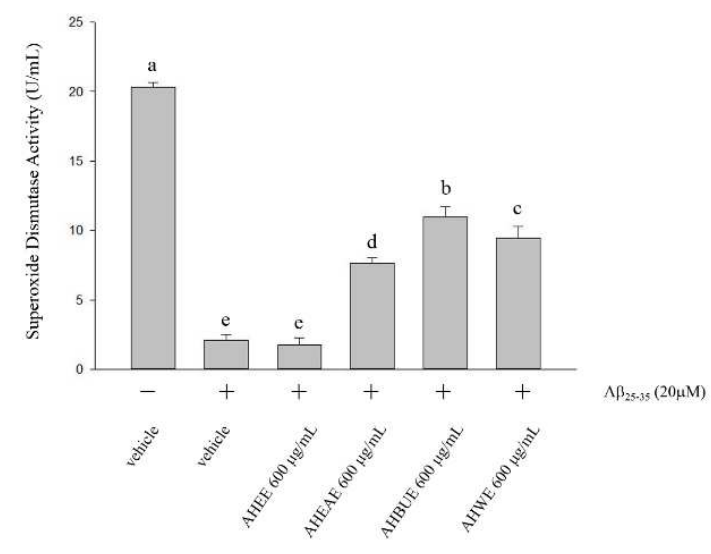

(b)

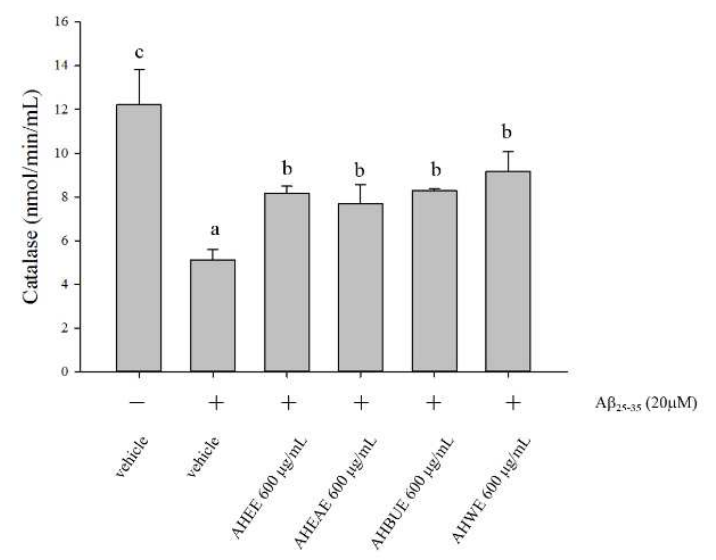

Fig. 5 Effects of the different adlay hull extracts on SOD (a) and CAT (b) activity in dPC12 cells. The values are the means \pm SD $(n=3)$ and analyzed using one-way ANOVA, followed by Duncan's new multiple range test. Bars that do not share a common letter are significantly different $(P<0.05)$ from each other. The cells were treated with $20 \mu \mathrm{MA} \beta_{25-35}$ to induce neurotoxicity. 


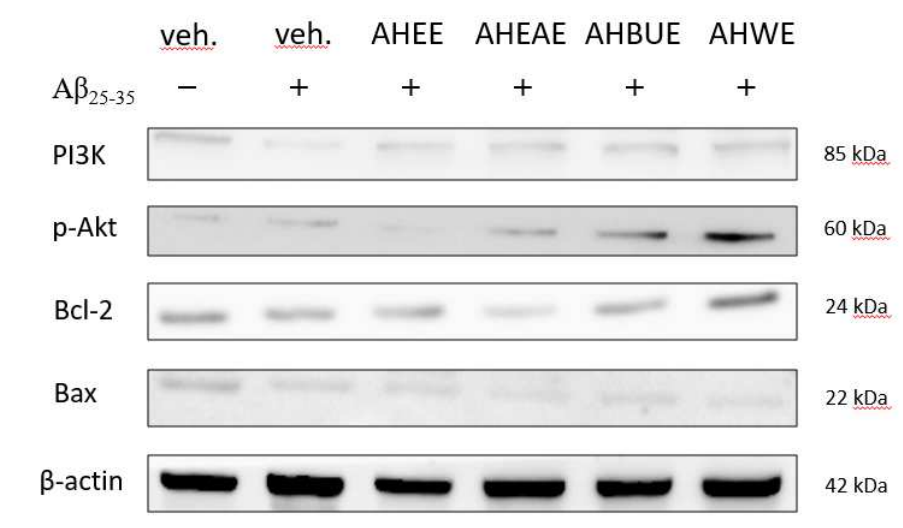

(a)

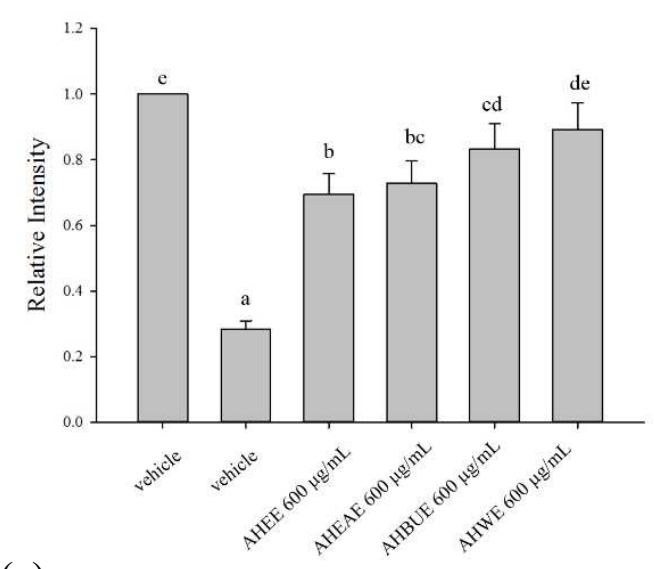

(c)

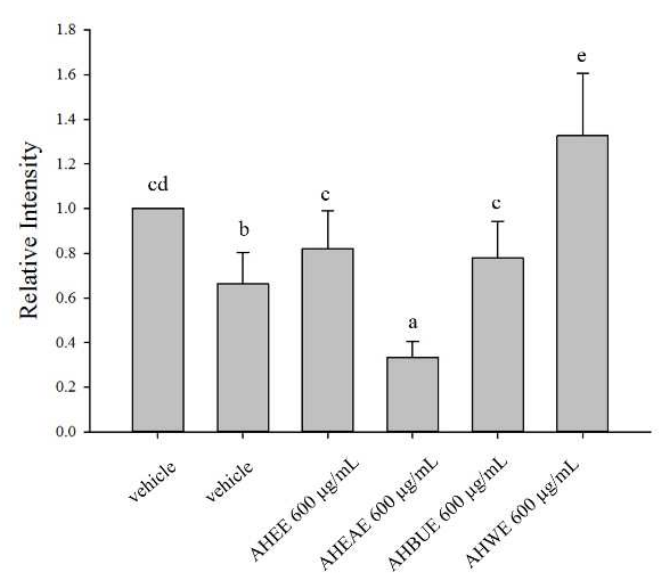

(b)

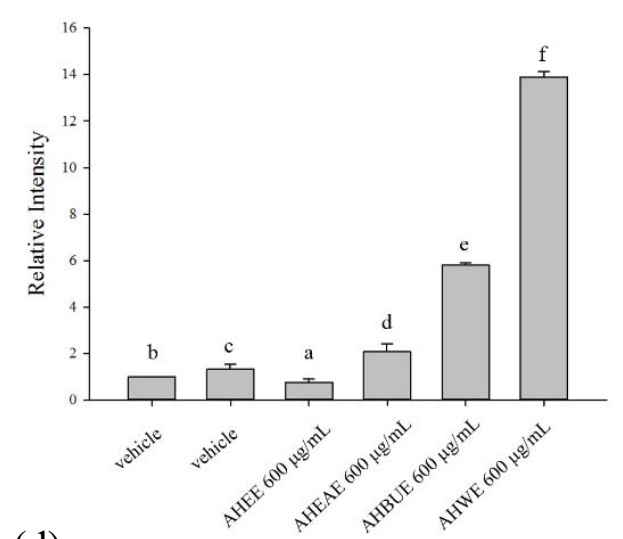

(d)

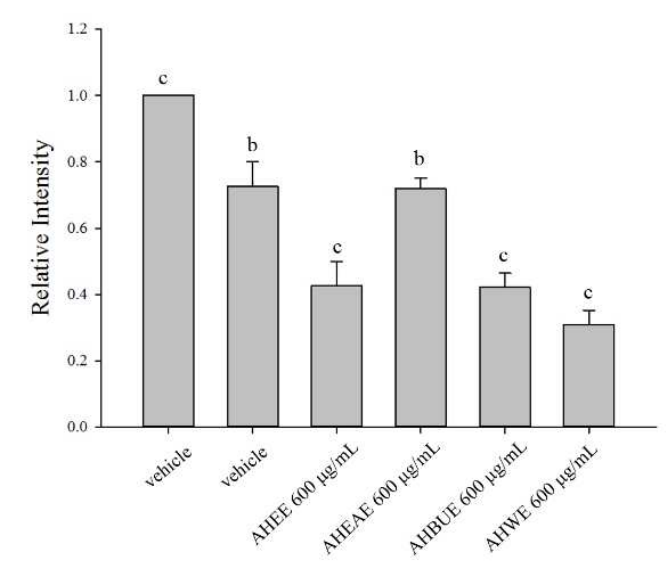

Fig. 6 Effects of the different adlay hull extracts on PI3K(a), p-Akt(b), Bcl-2(c), Bax(d) protein expression in dPC12 cells. The total cellular protein $(20 \mu \mathrm{g} /$ lane $)$ was separated on a $10 \%$ SDS-PAGE, transferred to a PVDF membrane and stained with antibodies. The values are the means $\pm \mathrm{SD}(\mathrm{n}=3)$ and analyzed using one-way ANOVA, followed by Duncan's new multiple range test. Bars that do not share a common letter are significantly different $(P<0.05)$ from each other. The cells were treated with $20 \mu \mathrm{M}$ $A \beta_{25-35}$ to induce neurotoxicity. 


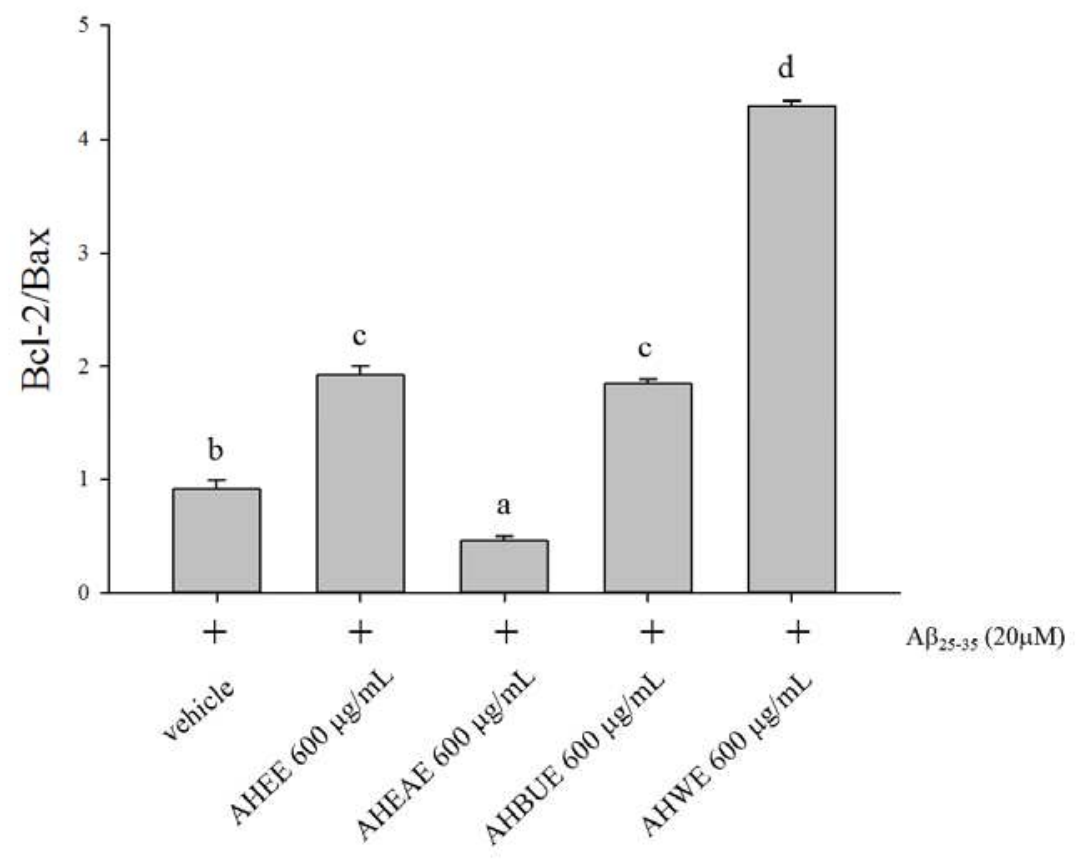

Fig. 7 Effects of the different adlay hull extracts on ratio of Bcl-2/Bax protein expression in $\mathrm{dPC} 12$ cells. The values are the means $\pm \mathrm{SD}(\mathrm{n}=3)$ and analyzed using one-way ANOVA, followed by Duncan's new multiple range test. Bars not sharing a common letter are significantly different $(P<0.05)$ from each other. The cells were treated with $20 \mu \mathrm{M} \mathrm{A} \beta_{25-35}$ to induce neurotoxicity. 


\section{Discussion}

\section{Antioxidant ability of different extracts of adlay hull}

In the in vitro antioxidant capacity test of different extracts of adlay hull, AHBUE was significantly better than other extracts in scavenging DPPH free radicals and the total phenol content. The experimental sample is the waste of adlay and the concept of waste reuse can create greater economic benefits for crops. The literature indicated that adlay contains special physiological functional components, such as coniferyl alcohol, syringic acid, ferulic acid, syringaresinol, 4-ketopinoresinol, campesterol, $\beta$-sitosterol, coixol, p-hydroxybenzaldehyde, syringaldehyde, vanillin, p-coumanc acid, gallic acid, vanillic acid, and flavonoids (naringenin, quercetin, tricin) and other phenolic compounds (Otsuka et al., 1988). Phenolic compounds are widely found in the plant kingdom. They can provide hydrogen ions in chemical reactions to inhibit the oxidation of free radicals and achieve the purpose of anti-oxidation. Flavonoids account for 80$90 \%$ of phenolic compounds. They are also widely found in the plant kingdom and have the best antioxidant capacity. DPPH-scavenging active components from adlay hulls were identified to be coniferyl alcohol, syringic acid, ferulic acid, syringaresinol, 4ketopinoresinol, and mayuenolide (Kuo et al., 2002). Our studies have found that the adlay hull contains a lot of phenolic compounds such as flavonoids, and the content of AHBUE was significantly higher than other extracts, and it also presents the best antioxidant capacity. This study also found that AHWE also has good antioxidant capacity in $\mathrm{dPC} 12$ cells for SOD and CAT, so it is speculated that it is caused by polyphenols.

\section{Anti-inflammatory ability of different extracts of adlay hull}

LPS induces inflammation in macrophages, and the inflammation process will acetylate the inflammatory cytokine genes (Cooper et al., 2010), it will aggravate the inflammation reaction, and a large amount of nitric oxide will be produced during the inflammation process. Nitric oxide (NO) is metabolized into nitrite (Nitrite), which acts as a mediator in the process of inflammation, enabling the synthesis of other inflammatory substances and jointly triggering the inflammatory response of the organism. In addition to their antioxidant capacity, phenolic compounds and flavonoids also inhibit LPS-induced inflammation in RAW264.7 (Chen et al., 2011). This study found that AHEE, AHEAE and AHWE all have the ability to inhibit the production of nitrite. Among them, AHEE and AHWE have a good ability to inhibit the production of nitrite at low concentrations, and are equal to the anti-inflammatory drug dexamethasone. NOS can be divided into three types, namely neuronal nitric oxide synthase (nNOS), endothelial nitric oxide synthase (eNOS) and inducible nitric oxide synthase (iNOS). It is important to note that iNOS plays an important role in the 
inflammation process. iNOS is mostly found in macrophages, lymphocytes and vascular smooth muscle cells, and it will synthesize a large amount of NO when stimulated by LPS (Nathan and Xie, 1994), cause cell damage and excessive vasodilation, and finally cause severe inflammation and complications (Rockey et $a l ., 1998)$. The literature pointed out that the main active ingredient after purification and separation of the ethyl acetate partition extract of the adlay hull contains two currently unknown compounds and six known compounds. They are coniferyl alcohol, 4-ketopinoresinol, phenolic compounds (p-vanillin, p-hydroxybenzaldehyde) and flavonoids (tricin, 5,7-dihydroxychromone), among which coniferyl alcohol and 4ketopinoresinol can inhibit the iNOS protein expression (Choi et al., 2015). This study found that AHEE, AHEAE and AHWE have good inhibition of iNOS protein, therefore, it is speculated that the experimental samples contain active ingredients such as coniferyl alcohol and 4-ketopinoresinol, and these two known active ingredients are natural phenolic compounds.

\section{Anti-apoptotic ability of different extracts of adlay hull}

Alzheimer's disease is a serious neurodegenerative disease, the brain with amnesia is accompanied by neuronal degeneration and damage, its main pathological features are tangled nerve fibers and deposition of $\beta$-amyloid peptide (Cuenco et al., 2008). The deposition of $\beta$-amyloid peptide will form free radicals, causing initial inflammation and damage and finally nerve cell death (Su et al., 2008). Studies have shown that both turmeric and tea contain polyphenolic compounds and have the ability to slow down the development of Alzheimer's disease (Bengmark et al., 2009). Undifferentiated PC12 cells are induced by nerve growth factor (NGF) to undergo differentiation, resulting in neurosynaptic outgrowth and branching. After differentiation, dPC12 cells can metabolize, store and secrete catecholamine neurotransmitters, including dopamine and norepinephrine, obviously showing the characteristics of mature sympathetic nerve cells and become nerve cells (Greene and Tischler, 1976). The literature pointed out that resveratrol can reduced apoptosis, decreased oxidative status and alleviated mitochondrial damage in $\mathrm{A} \beta_{1-42}$-treated PC12 cells (Wang et al., 2018). This study used $\mathrm{A} \beta_{25-35}$ to induce neurotoxicity in $\mathrm{dPC} 12$ cells, simulating the pattern of nerve cell damage in Alzheimer's disease, and conducting neuroprotection tests. This study found that AHWE has the best neuroprotective effect, it is speculated that the active ingredient of this sample to protect nerve cells is polyphenols. Studies have indicated that polyphenol compounds can increase the activity of antioxidant enzymes, such as catalase and superoxide dismutase (Bhullar and Rupasinghe, 2013).

The main molecular composition of nerve cell apoptosis includes the family of apoptotic proteins (Caspase), the Bcl-2 protein family and the activation factor of 
apoptotic protease-1 (Apaf-1). Neurotrophic factors regulate cell apoptosis key protein kinase signals, such as PI3K/Akt and mitogen-activated protein kinase (MAPK) pathways. In neurodegenerative diseases, similar cell death signaling pathways are activated by abnormal structural proteins, such as $\beta$-amyloid peptides in Alzheimer's disease (Yuan, 2000). The literature pointed out that the polyphenol compounds in berries can activate the PI3K/Akt pathway and achieve the ability to inhibit cell apoptosis (Aiyer et al., 2012). Phenolic compounds can increase the activity of antioxidant enzymes and activate Bcl-2 and PERK pathways, down-regulate Bid/Bax, c-jun, JNK, COX-2, AP-1 and caspase-3, and help nerve cell survival (Bhullar and Rupasinghe, 2013). This study found that AHWE has the ability to activate PI3K and p-Akt and increase the expression of anti-apoptotic protein (Bcl-2) and decrease proapoptotic protein $(\mathrm{Bax})$ protein. It is speculated that AHWE has anti-apoptotic activity and the active ingredient is polyphenol compounds. Among the tested compounds, quercetin and nobiletin significantly decreased the nitrite production in RAW264.7 cells (data not shown). These effects may result from to the combined actions of different compounds, indicating a possibility of a matrix effect from the compounds in adlay hull extract. Therefore, adlay hull extracts may be considered a feasible alternative as a therapeutic agent for neurodegenerative diseases.

\section{Conclusions}

This study found that AHBUE is significantly better than other extracts in scavenging DPPH free radicals and the total phenol content of antioxidant components. AHEE, AHEAE and AHWE can effectively inhibit the iNOS protein expression in RAW264.7 and inhibit the production of nitrite, the inflammatory mediator. AHWE increased PI3K, p-Akt and Bcl-2 in dPC12 cells and reduced the expression of Bax protein, inhibition of $A \beta$-induced neuronal apoptosis, achieving an anti-apoptotic effect by activating the PI3K/Akt pathway. According to the above results, the ethanol extract from the adlay hull and the partition extract with ethyl acetate have significant anti-inflammatory effects, while the partition extract from the water layer has both anti-inflammatory and neuroprotective effects, and has been developed as an anti-Alzheimer's health care food potential.

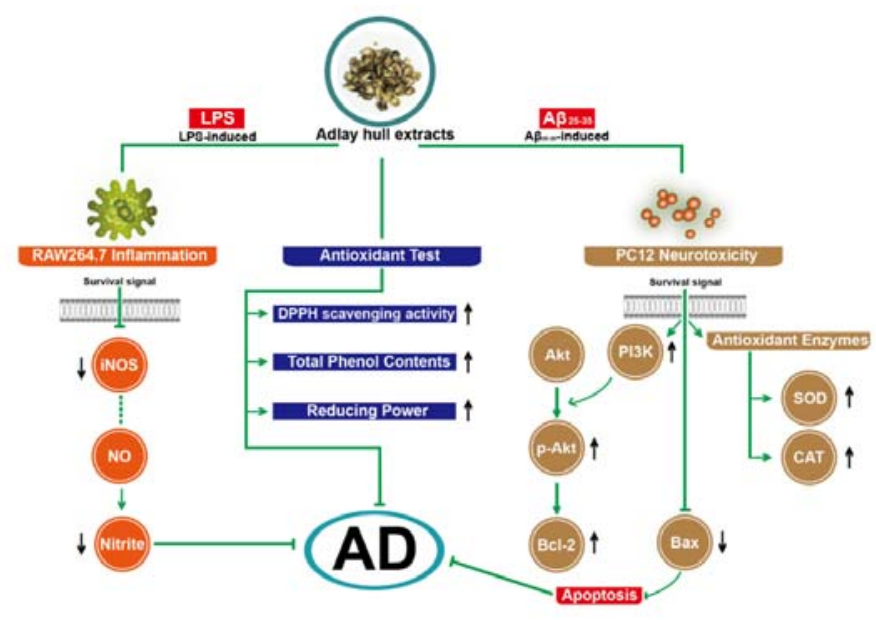




\title{
Supplementary information
}

\begin{abstract}
Abbreviations
AD: Alzheimer's disease; A $\beta$ : amyloid $\beta$; AHEE: ethanol extract of adlay hull; AHEAE: adlay hull ethanol extract partitioned by ethyl acetate; AHBUE: adlay hull ethanol extract partitioned by n-butanol; AHWE: adlay hull ethanol extract partitioned by water; ROS: reactive oxygen species; TCM: traditional Chinese medicine; FBS: fetal bovine serum; NGF: nerve growth factor; SOD: superoxide dismutase; CAT: catalase; Dex: dexamethasone.
\end{abstract}

\section{Acknowledgements}

The authors thank Chang-Hai Tsai, M.D., Ph.D. for his support and encouragement. Our gratitude also goes to Michael Burton, Asia University for his proofreading and editing.

\section{Authors' contributions}

GJT and CYC conceived the experiments. GJT, YTL and $\mathrm{CHH}$ performed the experiments, analyzed the results, and made figures and tables. FYT and CYC contributed to designing the experiments. CYC wrote the paper and supervised the study. YHK and YTL contributed to writing-review and editing. All authors read and approved the final manuscript.

\section{Funding}

This research project is supported by the grant of Ministry of Science and Technology (MOST), Taiwan, R.O.C. under the agreements MOST-105-2320-B-468-005. The study was supported in part by grant from Asia University and China Medical University Hospital (ASIA-108-CMUH-04) to Dr. Chao.

\section{Availability of data and materials}

The datasets used and/or analyzed during the current study are available from the corresponding author on reasonable request.

\section{Ethics approval and consent to participate}

Not applicable.

\section{Consent for publication}

All authors consent to publication of this study in the journal Chinese Medicine. 


\section{Competing interests}

The authors declare that they have no competing interests.

\section{Author details}

${ }^{1}$ Division of Immunology and Rheumatology, China Medical University Hospital, Taichung, Taiwan, R.O.C. ${ }^{2}$ College of Medicine, China Medical University, Taichung,

Taiwan, R.O.C. ${ }^{3}$ Division of Gastroenterology and Hepatobiliary, Asia University Hospital, Taichung, Taiwan, R.O.C. ${ }^{4}$ Department of Food Nutrition and Health Biotechnology, Asia University, Taichung, Taiwan, R.O.C. ${ }^{5}$ Biomedical Science Laboratory, Department of Nutrition, China Medical University, Taichung, Taiwan, R.O.C. ${ }^{6}$ Department of Chinese Pharmaceutical Sciences and Chinese Medicine Resources, China Medical University, Taichung, Taiwan, R.O.C. ${ }^{7}$ Department of Biotechnology, Asia University, Taichung, Taiwan, R.O.C. ${ }^{8}$ Chinese Medicine Research Center, China Medical University, Taichung, Taiwan, R.O.C. ${ }^{9}$ Department of Medical Research, China Medical University Hospital, China Medical University, Taichung, Taiwan, R.O.C.

§These authors contributed equally to this work.

\section{References}

1. Aiyer HS, Warri AM, Woode DR, Hilakivi-Clarke L, Clarke R. Influence of berry polyphenols on receptor signaling and cell-death pathways: implications for breast cancer prevention. J Agric Food Chem. 2012;60:5693-708.

2. Bengmark S, Mesa MD, Gil A. Plant-derived health: the effects of turmeric and curcuminoids. Nutr Hosp. 2009;24:273-81.

3. Bhullar KS, Rupasinghe HP. Polyphenols: multipotent therapeutic agents in neurodegenerative diseases. Oxid Med Cell Longev. 2013;2013:891748.

4. Chen HJ, Chung CP, Chiang W, Lin YL. Anti-inflammatory effects and chemical study of a flavonoid-enriched fraction from adlay bran. Food Chem. 2011;126: 1741-8.

5. Choi G, Han AR, Lee JH, Park JY, Kang U, Hong J, Seo EK. A comparative study on hulled adlay and unhulled adlay through evaluation of their LPS-induced antiinflammatory effects, and isolation of pure compounds. Chem Biodivers. 2015;12:380-7.

6. Chung CP, Hsia SM, Lee MY, Chen HJ, Cheng FW, Chan LC, Kuo YH, Lin YL, Chiang WC. Gastroprotective activities of adlay (Coix lachryma-jobi L. var. ma-yuen Stapf) on the growth of the stomach cancer AGS cell line and indomethacin-induced gastric ulcers. J Agric Food Chem. 2011;59:6025-33. 
7. Citron M. Alzheimer's disease: treatments in discovery and development. Nat Neurosci. 2002;5:1055-7.

8. Cooper ZA, Singh IS, Hasday JD. Febrile range temperature represses TNF-alpha gene expression in LPS-stimulated macrophages by selectively blocking recruitment of $\mathrm{Sp} 1$ to the TNF-alpha promoter. Cell Stress Chaperones. 2010;15:665-73.

9. Cuenco KT, Green RC, Zhang J, Lunetta K, Erlich PM, Cupples LA, Farrer LA, DeCarli C, MIRAGE Study Group. Magnetic resonance imaging traits in siblings discordant for Alzheimer disease. J Neuroimaging. 2008;18:268-75.

10. Greene LA, Tischler AS. Establishment of a noradrenergic clonal line of rat adrenal pheochromocytoma cells which respond to nerve growth factor. Proc Natl Acad Sci USA. 1976;73:2424-8.

11. Huang DW, Chung CP, Kuo YH, Lin YL, Chiang WC. Identification of compounds in adlay (Coix lachryma-jobi L. var. ma-yuen Stapf) seed hull extracts that inhibit lipopolysaccharide-induced inflammation in RAW 264.7 macrophages. J Agric Food Chem. 2009;57:10651-7.

12. Kim MJ, Lee J, Seong AR, Lee YH, Kim YJ, Baek HY, Kim YJ, Jun WJ, Yoon HG. Neuroprotective effects of Eriobotrya japonica against $\beta$-amyloid-induced oxidative stress and memory impairment. Food Chem Toxicol. 2011;49: 780-4.

13. Kuo CC, Chiang WC, Liu GP, Chien YL, Chang JY, Lee CK, Lo JM, Huang SL, Shih MC, Kuo YH. 2,2'-Diphenyl-1-picrylhydrazyl radical-scavenging active components from adlay (Coix lachryma-jobi L. var. ma-yuen Stapf) hulls. J Agric Food Chem. 2002;50:5850-5.

14. Long JM, Holtzman DM. Alzheimer disease: an update on pathobiology and treatment strategies. Cell. 2019;179:312-39.

15. Markesbery WR, Carney JM. Oxidative alternation in Alzheimer's disease. Brain Pathol. 1999;9:133-46.

16. Nathan C, Xie QW. Nitric oxide synthases: roles, tolls, controls. Cell. 1994;78: 915-8.

17. Otsuka H, Hirai Y, Nagao T, Yamaski K. Phenolic compounds from Coix lachrymal-jobi L var. ma-yuen. Phytochemistry. 1988;28:883-6.

18. Picone P, Nuzzo D, Giacomazza D, Carlo MD. $\beta$-amyloid peptide: the cell compartment multi-faceted interaction in Alzheimer's disease. Neurotox Res. 2020;37:250-63.

19. Rockey DC, Chung JJ, McKee CM, Noble PW. Stimulation of inducible nitric oxide synthase in rat liver by hyaluronan fragments. Hepatology. 1998;27:86-92.

20. Su B, Wang X, Nunomura A, Moreira PI, Lee HG, Perry G, Zhu X. Oxidative stress signaling in Alzheimer's disease. Curr Alzheimer Res. 2008;5:525. 
21. Wang H, Jiang T, Li W, Gao N, Zhang T. Resveratrol attenuates oxidative damage through activating mitophagy in an in vitro model of Alzheimer's disease. Toxicol Lett. 2018;5:100-8.

22. Wang LF, Chen JY, Xie HH, Ju XR, Liu RH. Phytochemical profiles and antioxidant activity of adlay varieties. J Agric Food Chem. 2013;61:5103-13.

23. Yao M, Nguyen TV, Pike CJ. Beta-amyloid-induced neuronal apoptosis involves c-Jun N-terminal kinase-dependent downregulation of Bcl-w. J Neurosci. 2005;25:1149-58.

24. Yu F, Gao J, Zeng Y, Liu CX. Effects of adlay seed oil on blood lipids and antioxidant capacity in hyperlipidemic rats. J Sci Food Agric. 2011;91:1843-8.

25. Yuan J, Yankner BA. Apoptosis in the nervous system. Nature. 2000;407:802-9. 
Figures

(a)

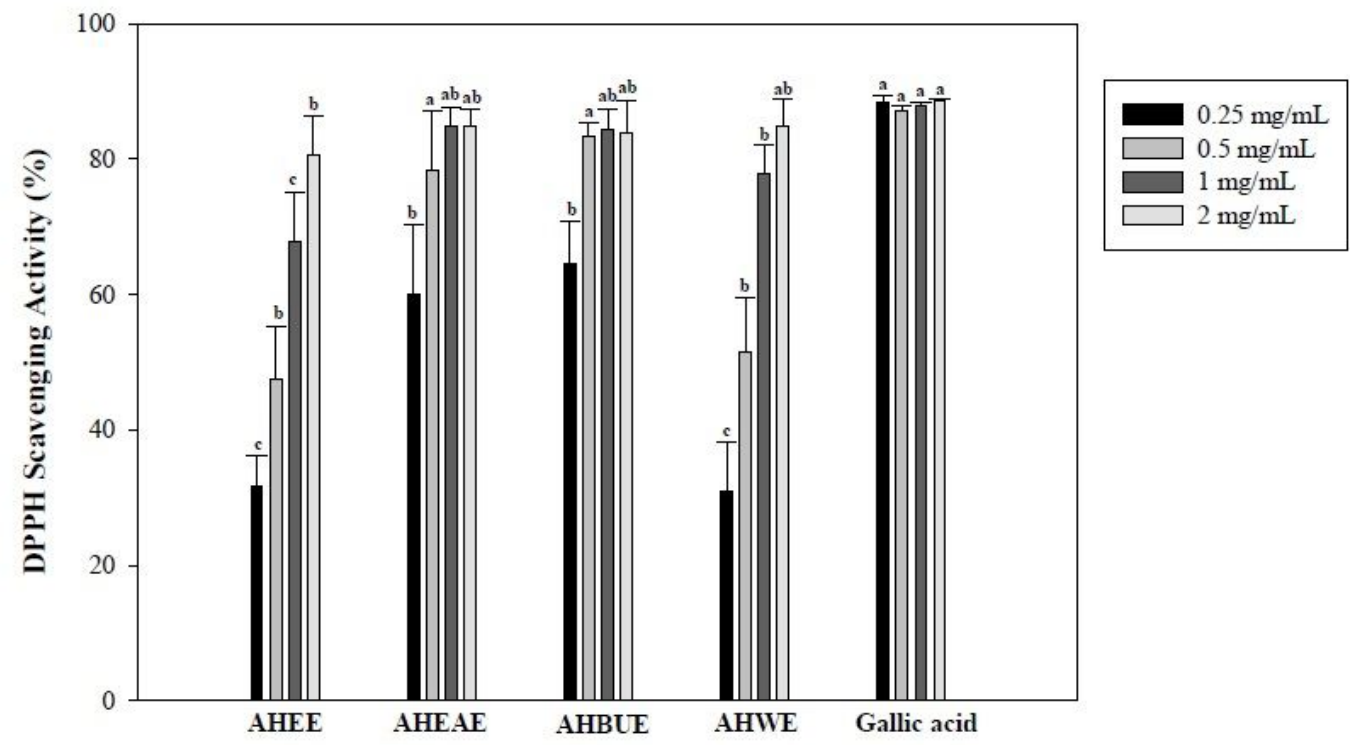

(b)

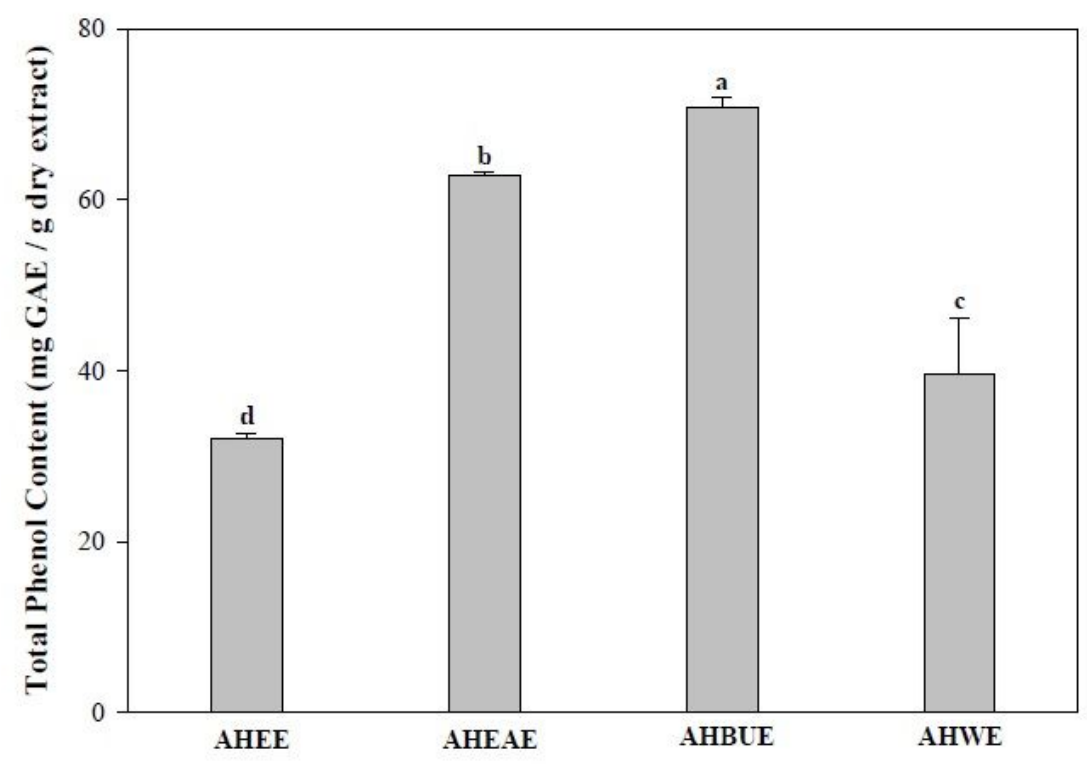

Figure 1

(a) The DPPH scavenging activity of the adlay hull extracts. (b) The total phenol contents of the adlay hull extracts. The values are the means \pm SD $(n=3)$ and analyzed using one-way ANOVA, followed by Duncan's new multiple range test. The superscript letters indicate significant differences $(P<0.05)$. 


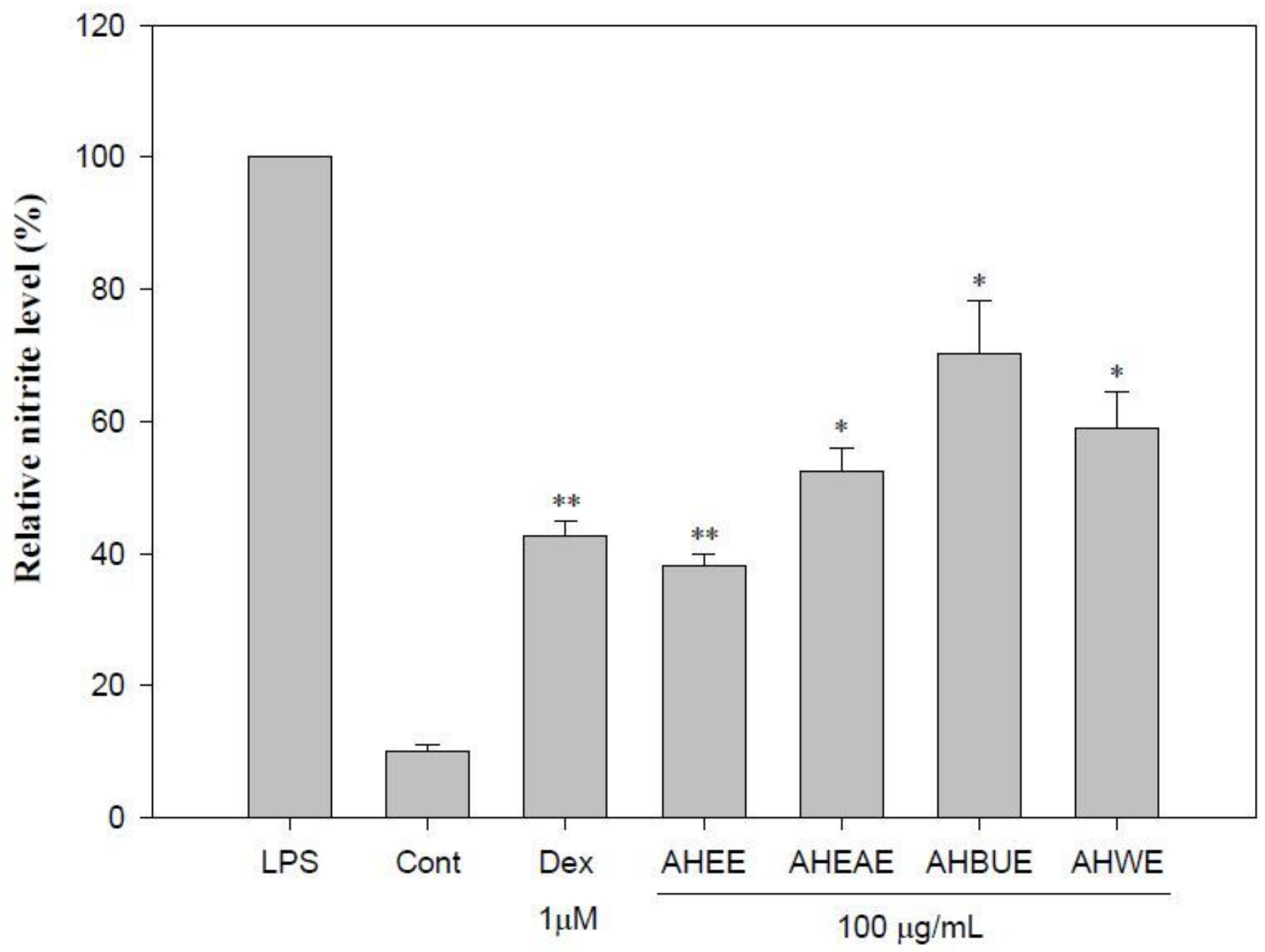

Figure 2

Effects of the different adlay hull extracts on nitrite production in RAW264.7 cells. The values are the means $\pm S D(n=3)$ and statistical analysis was done using the Student's t-test. ${ }^{*} P<0.01 ; * * P<0.001$, were significantly different from the control group. Dexamethasone at the concentration of $100 \mathrm{M}$ was used as a positive control; cells were treated with $100 \mathrm{ng} / \mathrm{mL}$ LPS to induce inflammation. 
iNOS

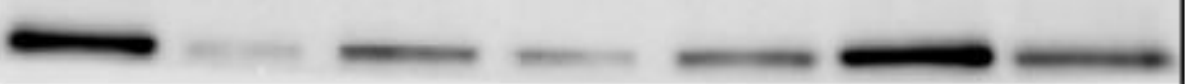

GAPDH
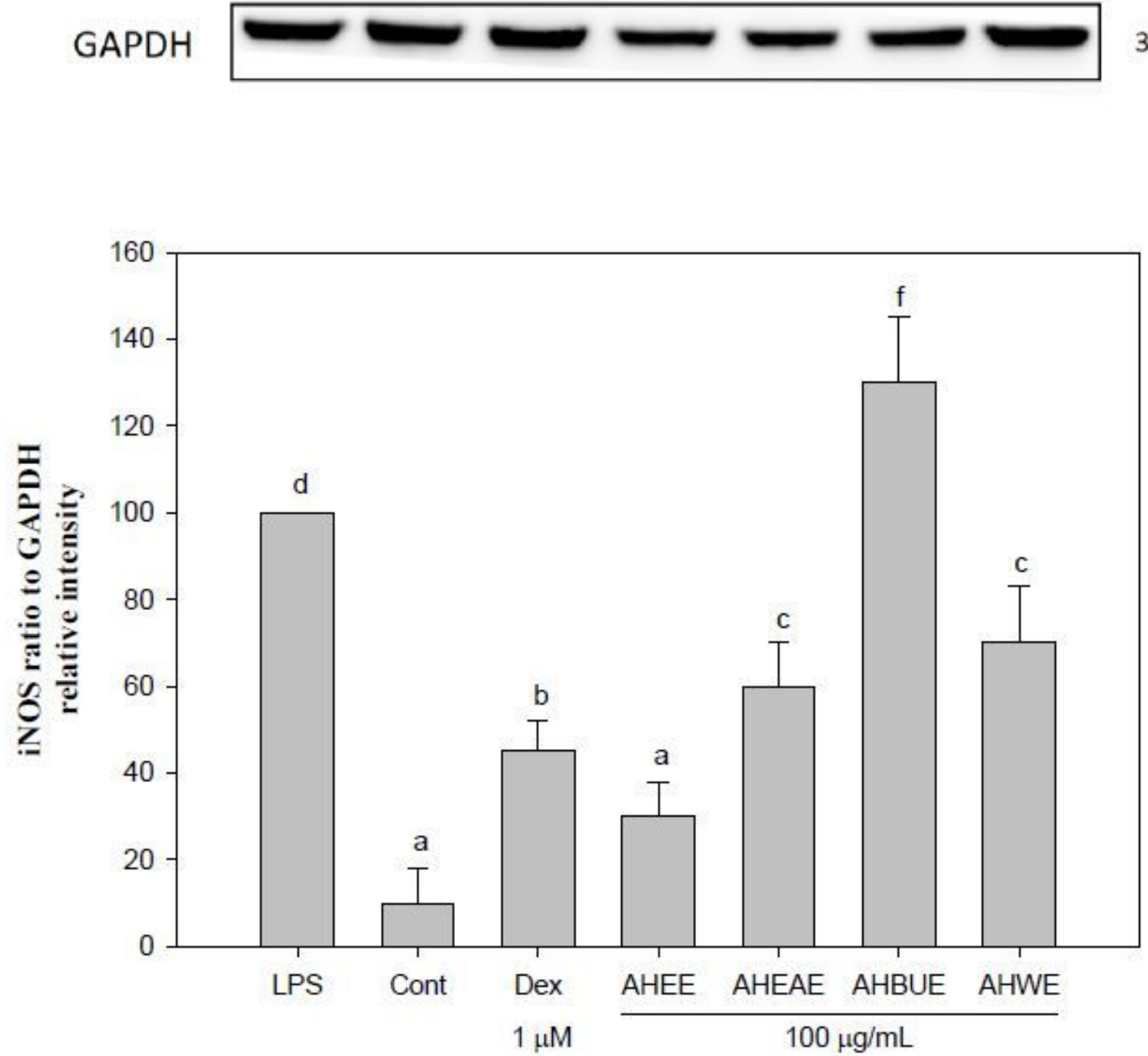

Figure 3

Effects of the different adlay hull extracts on iNOS protein expression in RAW264.7 cells. The total cellular protein ( $20 \mu \mathrm{g} / \mathrm{lane})$ was separated on a 10\% SDSPAGE, transferred to a PVDF membrane and stained with antibodies specific for iNOS. The values are the means $\pm S D(n=3)$ and analyzed using oneway ANOVA, followed by Duncan's new multiple range test. Bars that do not share a common letter are significantly different (Pख0.05) from each other. Dexamethasone at the concentration of $100 \mathrm{M}$ was used as a positive control; cells were treated with $100 \mathrm{ng} / \mathrm{mL}$ LPS to induce inflammation. 


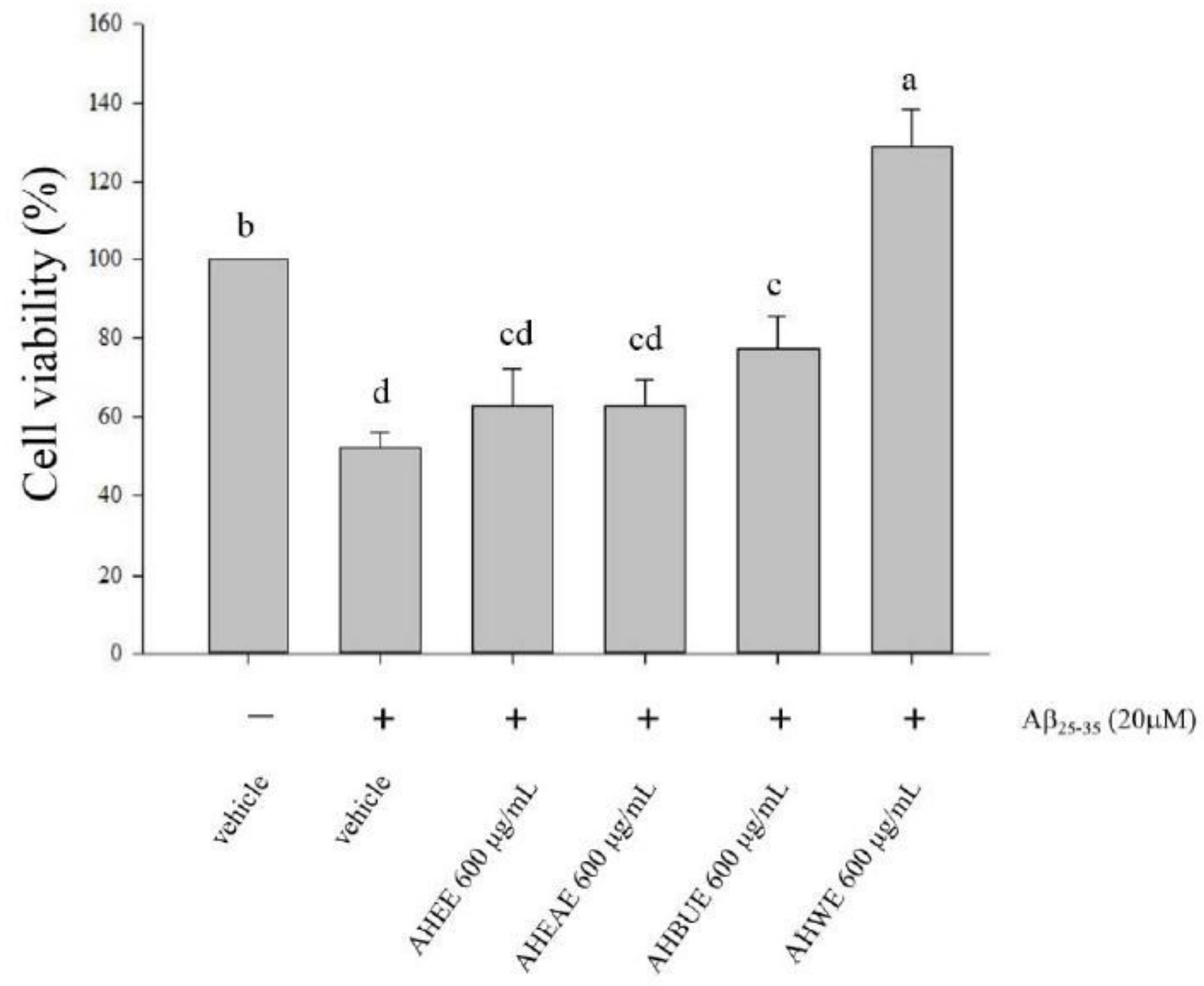

Figure 4

MTT assay of the different adlay hull extracts to neuroprotection in dPC12 cells. The values are the means $\pm S D(n=3)$ and analyzed using one-way ANOVA, followed by Duncan's new multiple range test. Bars that do not share a common letter are significantly different (Pख0.05) from each other. The cells were treated with $20 \mu \mathrm{M} A \beta 25-35$ to induce neurotoxicity. 
(a)

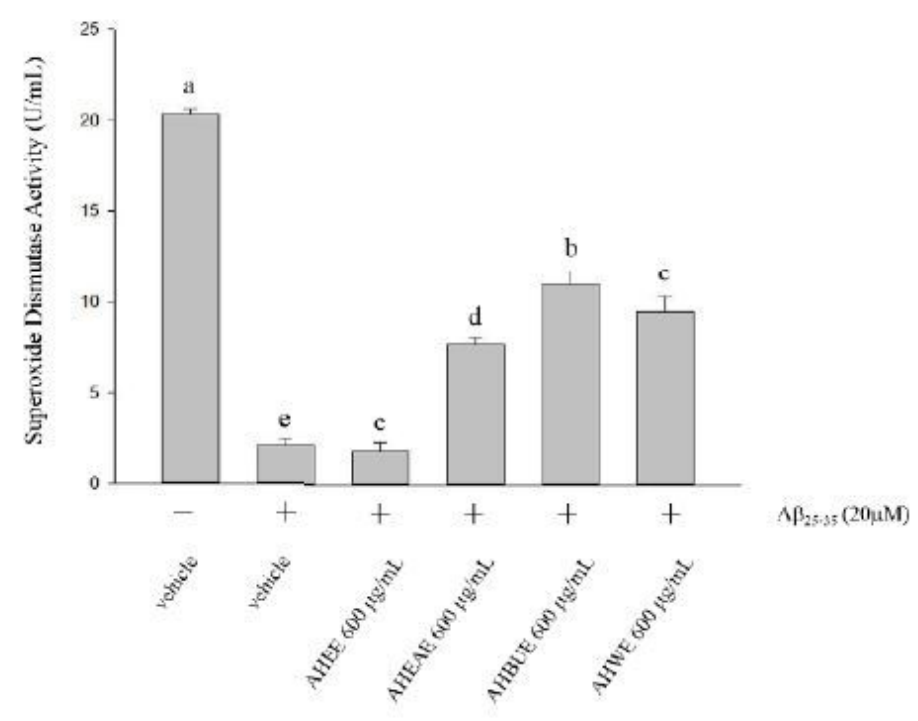

(b)

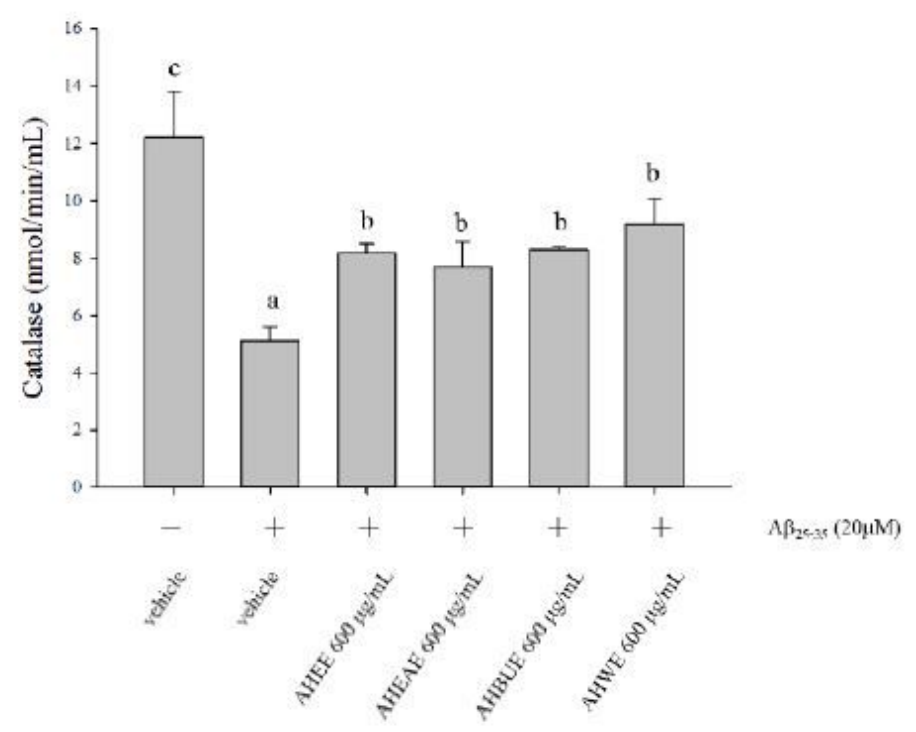

\section{Figure 5}

Effects of the different adlay hull extracts on SOD (a) and CAT (b) activity in dPC12 cells. The values are the means $\pm S D(n=3)$ and analyzed using one-way ANOVA, followed by Duncan's new multiple range test. Bars that do not share a common letter are significantly different (Pख0.05) from each other. The cells were treated with $20 \mu \mathrm{M} \mathrm{A \beta 25-35}$ to induce neurotoxicity. 
veh. veh. AHEE AHEAE AHBUE AHWE

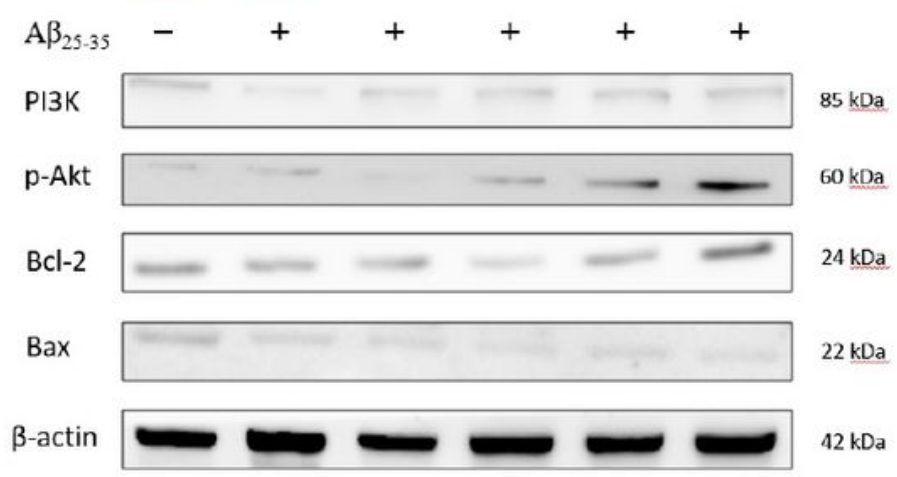

(a)

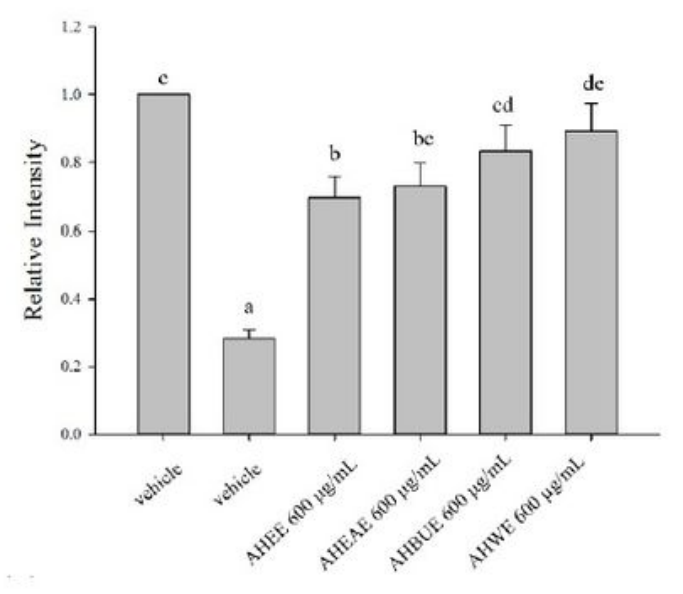

(c)

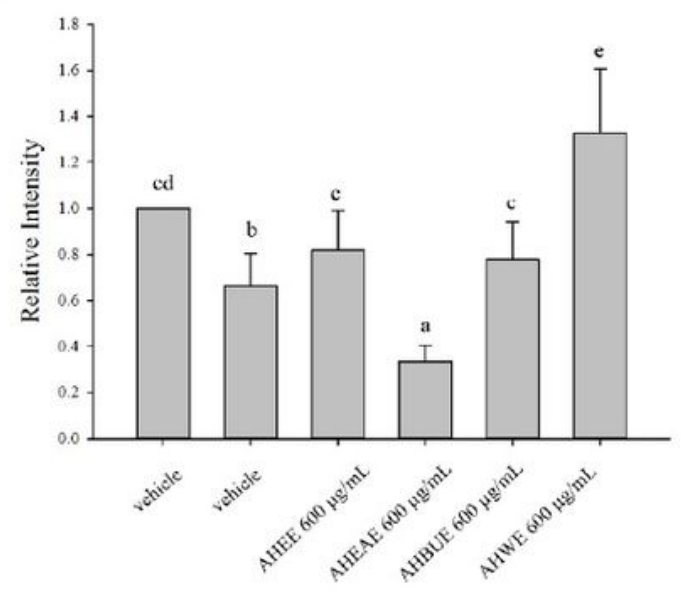

(b)

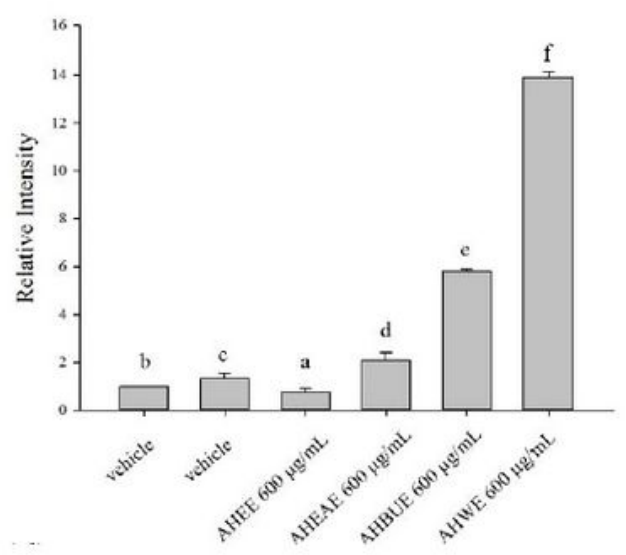

(d)

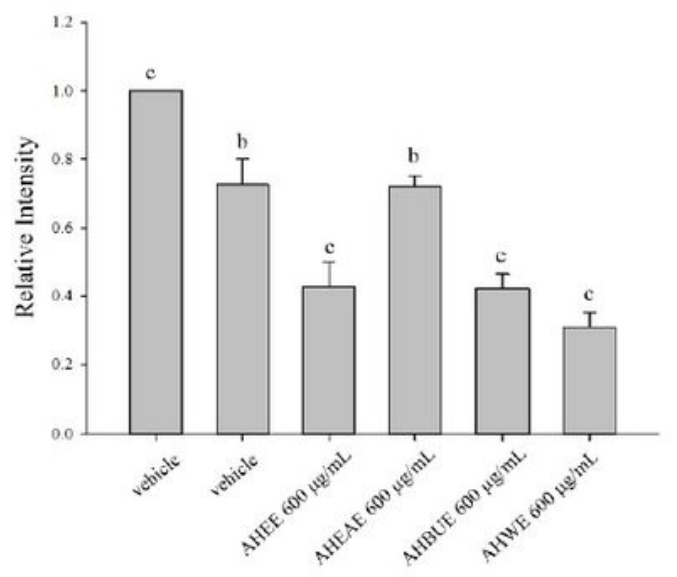

\section{Figure 6}

Effects of the different adlay hull extracts on PI3K(a), p-Akt(b), Bcl-2(c), Bax(d) protein expression in dPC12 cells. The total cellular protein $(20 \mu \mathrm{g} /$ lane) was separated on a $10 \%$ SDS-PAGE, transferred to a PVDF membrane and stained with antibodies. The values are the means \pm SD $(n=3)$ and analyzed using one-way ANOVA, followed by Duncan's new multiple range test. Bars that do not share a common letter 
are significantly different $(\mathrm{P} \bigotimes 0.05)$ from each other. The cells were treated with $20 \mu \mathrm{M} A \beta 25-35$ to induce neurotoxicity.

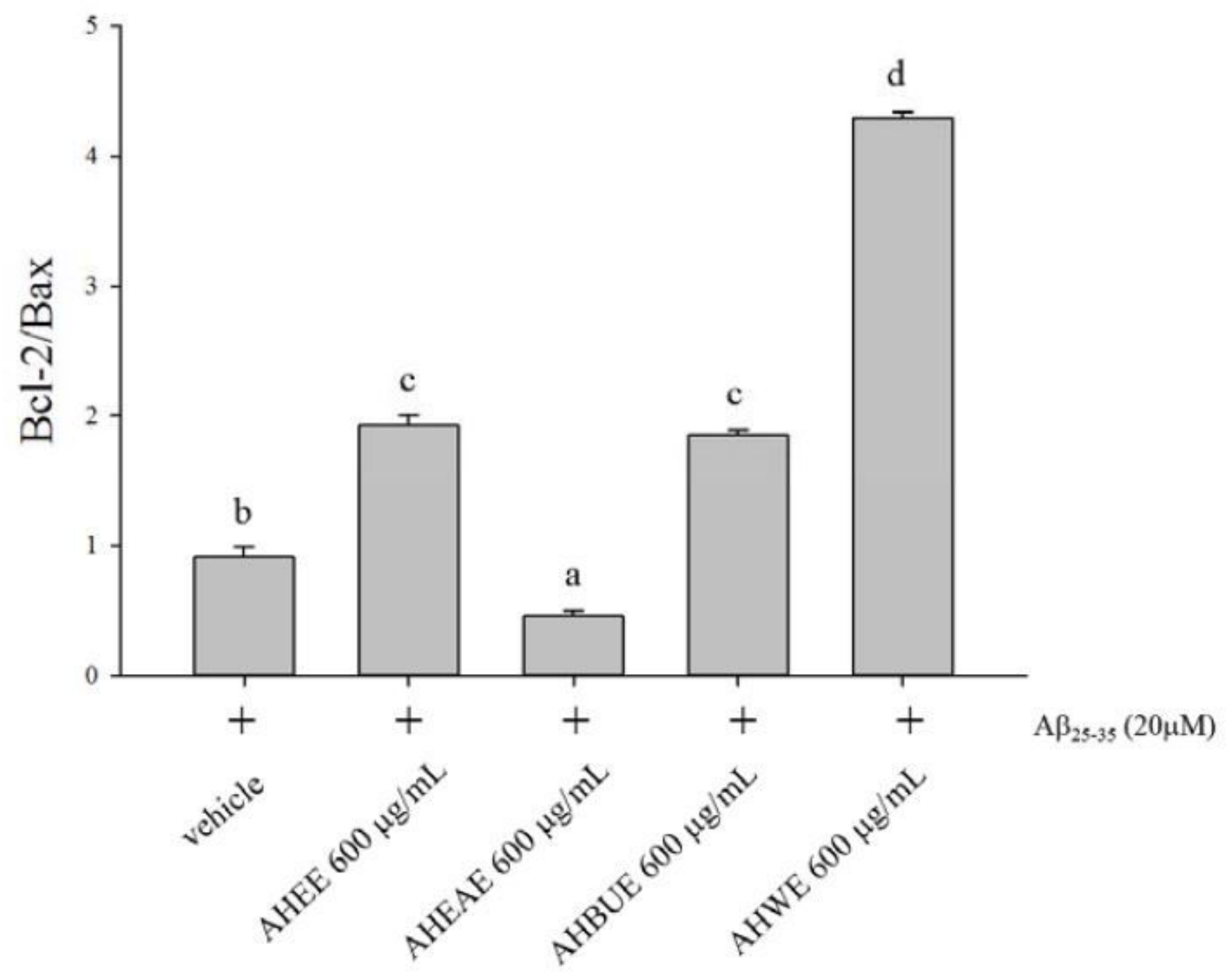

Figure 7

Effects of the different adlay hull extracts on ratio of Bcl-2/Bax protein expression in dPC12 cells. The values are the means $\pm S D(n=3)$ and analyzed using one-way ANOVA, followed by Duncan's new multiple range test. Bars not sharing a common letter are significantly different ( $\mathrm{P} \otimes 0.05)$ from each other. The cells were treated with $20 \mu \mathrm{M} \mathrm{A} 25-35$ to induce neurotoxicity. 